\section{To: (Receiving Organization) \\ Spent Nuclear Fuel \\ Conditioning Projects}

5. Proj./Prog./Dept./Div.:

Spent Nuclear Fuel Project

8. Originator Remarks:

For Release

11. Receiver Remarks:

11A. Design Basel ine Document? $[\mathrm{X}]$ Yes
4. Related EDT No.:

N/A

6. Design Authority/ Design Agent/Cog. Engr.:

A. L. Pajunen

$\mathrm{N} / \mathrm{A}$
7. Purchase Order No.:

9. Equip./Component No.:

$\mathrm{N} / \mathrm{A}$

10. System/Bldg./Facility:

$\mathrm{N} / \mathrm{A}$

12. Major Assm. Dwg. No.:

N/A

13. Permit/Permit Application No.: N/A

14. Required Response Date:

N/A

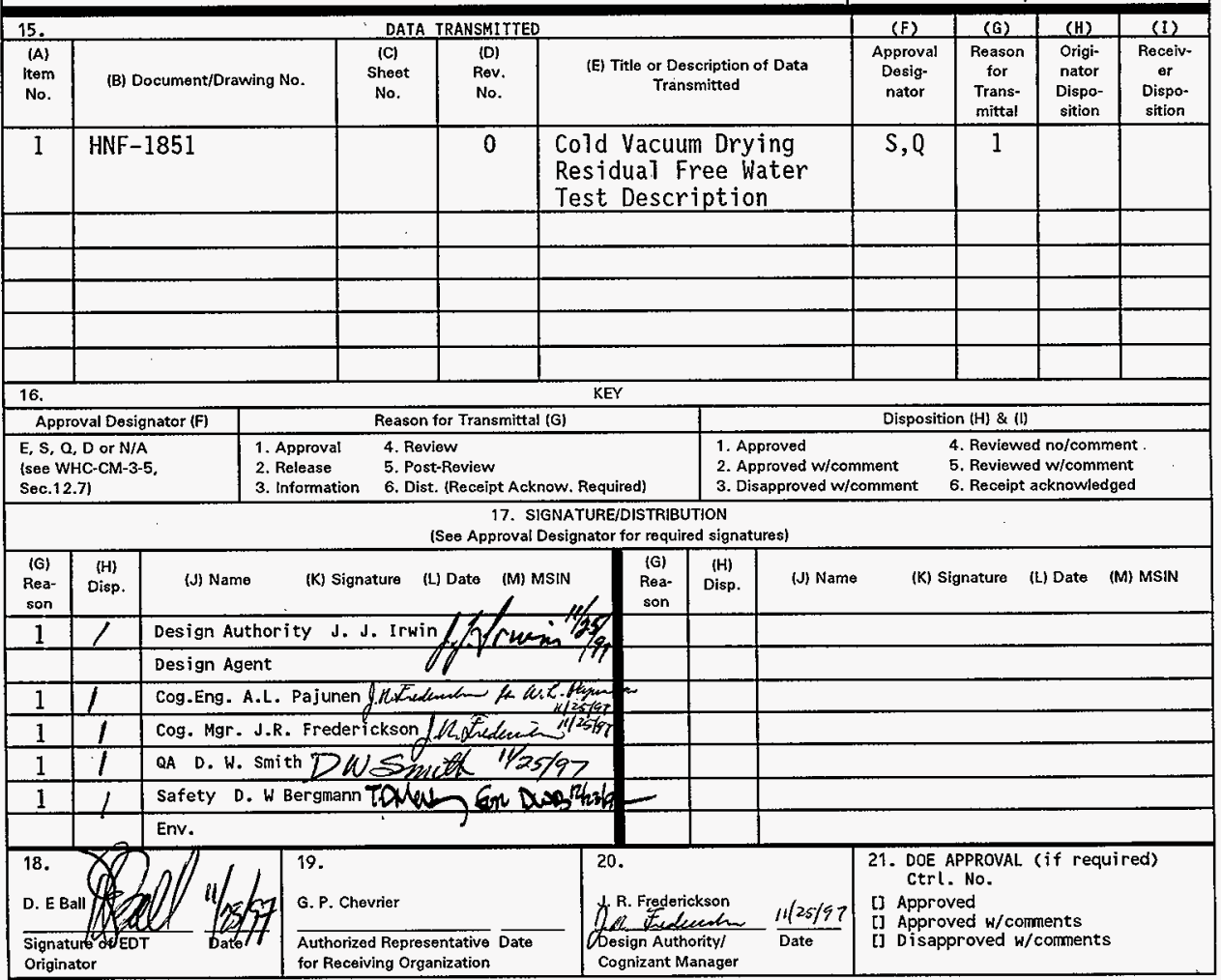

BD -7400-172-2 (05/96) GEF097 
HNF-1851, Rev 0

\title{
Cold Vacuum Drying Residual Free Water Test Description
}

\author{
A. L. Pajunen
}

SGN Eurisys Services Corporation, Richland, WA 99352

U.S. Department of Energy Contract DE-AC06-96RL13200

$\begin{array}{lll}\text { EDT/ECN: } & 616193 & \text { UC: } 510 \\ \text { Org Code: } & 2 T 710 & \text { Charge Code: } L B 051 \\ \text { B\&R Code: } & \text { EW3135040 } & \text { Total Pages: } 68\end{array}$

Key Words: N-Reactor Fuel, CVD process, Free Water

Abstract: Residual free water expected to remain in a Multi-Canister Overpack (MCO) after processing in the Cold Vacuum Drying (CVD) Facility is investigated based on three alternative models of fuel crevices.

Tests and operating conditions for the CVD process are defined based on the analysis of these models. The models consider water pockets constrained by cladding defects, water constrained in a pore or crack by flow through a porous bed, and water constrained in pores by diffusion. An analysis of comparative reaction rate constraints is also presented indicating that a pressure rise test can be used to show MC0's will be thermally stable at operating temperatures up to $75^{\circ} \mathrm{C}$.

TRADEMARK DISCLAIMER. Reference herein to any specific comercial product, process, or service by trade name, trademark, manufacturer, or otherwise, does not necessarily constitute or imply its endorsement, recommendation, or favoring by the United States Government or any agency thereof or its contractors or subcontractors.

Printed in the United States of America. To obtain copies of this document, contact: Document Control Services, P.0. Box 950, Mailstop H6-08, Richland WA 99352, Phone (509) 372-2420;

Fax (509) 376-4989.
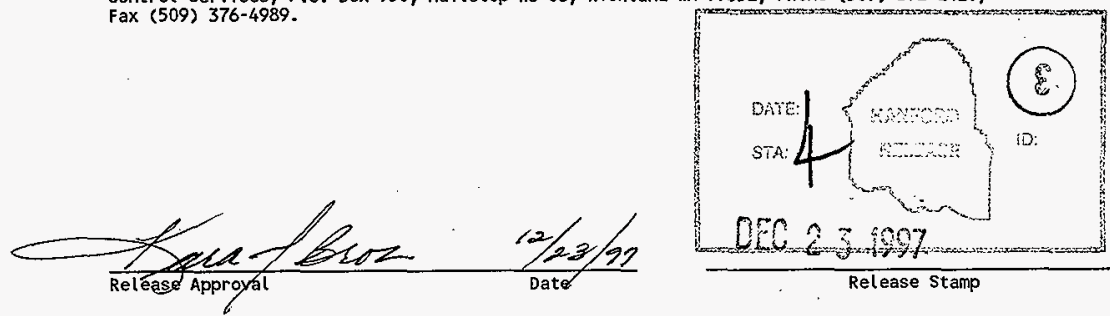


\author{
HNF-1851, Rev 0 \\ COLD VACUUM DRYING RESIDUAL FREE WATER \\ TEST DESCRIPTION
}

Table of Contents

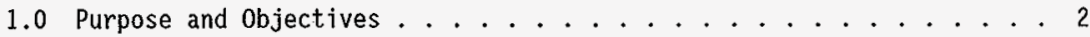

2.0 Summary of Results and Conclusions ............. 2

3.0 Software Applications ................ 5

4.0 Input Data .................... 5

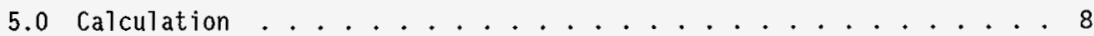

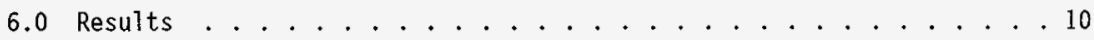

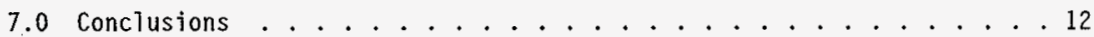

8.0 References . . . . . . . . . . . . . . . 12

9.0 Appendices ........................ . . . 14

9.1 Drying Performance using an Orifice Flow Model . . . . . . . . . 14

9.2 Drying Performance using a Porous Bed Flow Model . . . . . . 31

9.3 Drying Performance using a Pore Diffusion Model . . . . . . . 49

9.4 Pressure Rise Test Uncertainty Estimate . . . . . . . . . . . . 57

9.5 Cold Vacuum Drying Operating Stability at $75^{\circ} \mathrm{C} \ldots . . .62$ 


\section{HNF-1851, Rev 0 \\ COLD VACUUM DRYING RESIDUAL FREE WATER \\ TEST DESCRIPTION}

\subsection{Purpose and Objectives}

The purpose of this calculation is to develop the basis for using a pressure rise test during cold vacuum drying to demonstrate that the residual free water inventory of an MCO is less than a selected criterion. Residual free water is that which remains constrained within fuel and cladding defects. All other free water is considered to be removed during the CVD process. The calculation objective includes documentation of the test basis and definition of the required test conditions. The test definition is considered complete by specifying, for a pre-selected allowable residual water mass, the test temperature, pressure range, and duration required to demonstrate residual water has been reduced to within the desired criterion.

\subsection{Summary of Results and Conclusions}

Three fuel crevice drying models were developed to characterize drying times once unconstrained free water is removed from an MCO by the CVD process. Two models, based on water vapor flow, were developed as alternative descriptions of vacuum operating conditions (see Figures 5-1[A] and [B]). A diffusion model (Figure $5-1[\mathrm{C}]$ ) is used to characterize a flowing helium operating mode. It should be emphasized that configurations modeled were selected to address as many crevice conditions as possible. Cracks that may be modeled as Figure 5-1[B] or [C] are apparent in fuel characterization observations. However, no pockets resembling the configuration in Figure 5$1[A]$ have been found to date and is included in this analysis for conservatism. Since pockets have not observed, the residual water was analyzed as existing in each configuration, independently. Combining the pocket and crack inventory estimates from these analyses was considered overly conservative, since each individual configuration analys is is in itself conservative.

Table 2-1 summarizes two alternatives for test and operating procedures that demonstrate an MCO contains less than $200 \mathrm{~g}$ of residual free water. The first alternative consists of three steps or activities based on first completing the vacuum drying cycles. The first step consists of holding the MCO in helium to ensure that internal fuel temperatures are above the test temperature assumed in the basis calculations. A pressure rise test is then performed which can serve two purposes. The pressure rise test is capable of 


$$
\text { HNF-1851, Rev } 0
$$

demonstrating that the MCO residual free water inventory is less than $200 \mathrm{~g}$ based on the orifice flow model of water pockets. In addition, the test indicates that it is feasible to increase the MCO to higher temperatures. Demonstrating safe operation at higher temperature based on the reacting surface area was found to produce the most restrictive criterion for the pressure rise test.

Evaluation of the MCO residual water inventory based on the porous bed and pore diffusion model and a pressure rise test does not appear to be feasible. However, it is feasible to predict that the water inventory is reduced below $200 \mathrm{~g}$ by these models if the MCO is held at a particular temperature for a specified time period. The third step of Alternative 1 shown in Table 2-1 is based on removing water from these cracks assuming that the predominant crack or pore length is $5 \mathrm{~cm}$ long and the pore diffusion mode1. An operating temperature above $65^{\circ} \mathrm{C}$ was found to be required to achieve reasonable operating times for this alternative.

The second alternative shown in Table 2-1 is based on extending the vacuum operating cycles used to remove bulk water for the MCO. It again is based on establishing that fuel temperatures are greater than $40^{\circ} \mathrm{C}$ prior to performing a pressure rise test. The pressure rise criterion in the second step is slightly greater in this alternative, as the test is only used to demonstrate water pocket inventories are less than $200 \mathrm{~g}$ (operation at temperatures above $50^{\circ} \mathrm{C}$ is not required).

The third step of Alternative 2 is based on removing water from cracks assuming the predominant crack or pore length is $5 \mathrm{~cm}$ long and the porous bed flow model. As with Alternative 1, the specified time was found to be appljcable for a bounding crack volume assuming all cracks are $5 \mathrm{~cm}$ long, or a simple distribution of crack lengths around $5 \mathrm{~cm}$.

Table 2-1 also provides a comparison of the approximate cycle time associated with the alternative test/operation approaches. Alternative 1 has a shorter overall cycle, but requires that the $M C O$ be heated to higher temperatures. Based on the analyses available to date, Alternative 2 provides the most conservative bases for a test/operating procedure concluding MCOs contain less than $200 \mathrm{~g}$ residual free water. Using Alternative 2 as the test basis maximizes the potential impact on cycle time. However, significant opportunity exists for reducing the time associated with this test if thermal analyses are completed to demonstrate that vacuum operation at temperatures 
Table 2-1. Alternative Test and operating requirements to demonstrate MCO residual free water is less than $200 \mathrm{~g}$.

\begin{tabular}{|c|c|c|c|c|}
\hline Alternative & Testoperation element & Description & Basis & $\begin{array}{l}\text { Cycle time } \\
\text { required, hr }\end{array}$ \\
\hline \multirow{3}{*}{1} & 1. Pressure rise test preparation & $\begin{array}{l}\text { - Hold fuel/MCO in stagnant or flowing } \\
\text { helium for } \geq 4 \mathrm{hr} \text { prior to test }\end{array}$ & $\begin{array}{l}\text { - Fuel and scrap temperature in MCO must be }>40^{\circ} \mathrm{C} \text { for } \\
\text { test calculation bases to be valid }\end{array}$ & 4 \\
\hline & $\begin{array}{l}\text { 2. Perform pressure rise test at } \\
\text { temperature } 240^{\circ} \mathrm{C}\end{array}$ & $\begin{array}{l}\text { - Evacuate MCO to } \leq 10 \text { torr } \\
\text { - Show pressure rise } \leq 2.6 \text { torr } / \mathrm{hr} \\
\text { - Test duration } 21 \mathrm{hr}\end{array}$ & $\begin{array}{l}\text { - Condition for orifice flow model validity and to obtain } \\
\text { acceptable measurement sensitivity. } \\
\text { - Indicates thermal stability at up to } 75^{\circ} \mathrm{C} \text { and water }<200 \mathrm{~g} \\
\text { by orifice flow model. } \\
\text { - Required for reduction of mass rate uncertainty from } \\
\text { pressure rise. }\end{array}$ & 1 \\
\hline & $\begin{array}{l}\text { 3. Perform fuel pore drying at } \\
\text { temperature } z 65^{\circ} \mathrm{C}\end{array}$ & $\begin{array}{l}\text { - Heat MCO such that fuel temperature } z \\
65^{\circ} \mathrm{C} \text {. } \\
\text { - MCO helium backfill pressure } \leq 1000 \text { torr. } \\
\text { - Helium flow such that partial pressure } \\
\text { water }<30 \text { torr. } \\
\text { - Time at } 65^{\circ} \mathrm{C} \text { is } \geq 20 \mathrm{hr} \text {. }\end{array}$ & $\begin{array}{l}\text { - Conditions for residual water }<200 \mathrm{~g} \text { based on pore } \\
\text { diffusion model and cracks predominantly }<5 \mathrm{~cm} \text { long. }\end{array}$ & $\begin{array}{l}26^{(4)} \\
\frac{31}{4}\end{array}$ \\
\hline \multirow{3}{*}{2} & 1. Pressure rise test preparation & $\begin{array}{l}\text { - Hold fuel/MCO in stagnant or flowing } \\
\text { helium for } \geq 4 \mathrm{hr} \text { prior to test }\end{array}$ & $\begin{array}{l}\text { - Fuel and scrap temperature in MCO must be }>40^{\circ} \mathrm{C} \text { for } \\
\text { test calculation bases to be valid }\end{array}$ & 4 \\
\hline & $\begin{array}{l}\text { 2. Perform pressure rise test at } \\
\text { temperature } 240^{\circ} \mathrm{C}\end{array}$ & $\begin{array}{l}\text { - Evacuate MCO to } \leq 10 \text { torr } \\
\text { - Show pressure rise } \leq 3 \text { torr } / \mathrm{hr} \\
\text { - Test duration } 21 \mathrm{hr}\end{array}$ & $\begin{array}{l}\text { - Condition for orifice flow model validity and to obtain } \\
\text { acceptable measurement sensitivity. } \\
\text { - Indicates water < } 200 \mathrm{~g} \text { by orifice flow model. } \\
\text { - Required for reduction of mass rate uncerfainty from } \\
\text { pressure rise. }\end{array}$ & 1 \\
\hline & $\begin{array}{l}\text { 3. Perform fuel pore drying at } \\
\text { temperature } 240^{\circ} \mathrm{C}\end{array}$ & $\begin{array}{l}\text { - Maintain fuel at }>40^{\circ} \mathrm{C} \\
\text { - Maintain MCO pressure at } \leq 20 \text { torr for a } \\
\text { total time } \approx 20 \mathrm{hr}^{(1)}\end{array}$ & $\begin{array}{l}\text { - Conditions for residual water }<200 \mathrm{~g} \text { based on porous } \\
\text { bed model. }{ }^{(2)}\end{array}$ & $\frac{32^{(3)}}{37}$ \\
\hline
\end{tabular}

Notes: (1) The total time at vacuum is not required to be a single continuous time period for the model results to be applicable. That is, the time can be broken up into multiple segments (e.g., four $5 \mathrm{hr}$ time periods).

(2) The time period to satisfy the $200 \mathrm{~g}$ limit by the porous bed model could be significantly reduced (to $\sim 3 \mathrm{hr}$ ) if higher temperature operation (e.g., $>60^{\circ} \mathrm{C}$ ) can be demonstrated to be thermally stable during vacuum operation. This is not done by the hand calculation in Section 9.5 , but may be possible using computer models.

(3) Total cycle time estimate based on allowing $6 \mathrm{hr}$ at vacuum followed by $4 \mathrm{hr}$ at helium flow to ensure thermal stability. This results in $(6+4)+(6+4)+(6+4)+2=32 \mathrm{hr}$ cycle time to obtain $20 \mathrm{hr}$ of vacuum operation.

(4) Assumes $6 \mathrm{hr}$ heat up period, neglects cycle time addition to cool MCO at end of cycle. 
above $50^{\circ} \mathrm{C}$ are viable or a periodic helium addition can be eliminated from the vacuum operating cycle once water is constrained by fuel crevices.

\subsection{Software Applications}

This calculation is basically a hand calculation. The spreadsheet software application, Quattro ${ }^{\circledR}$ Pro for Windows - Version 5.0, was used to replicate the calculations and graph results. The software calculations were treated as hand calculations and example calculations were used to check the spreadsheet input.

(Quattro ${ }^{\circledR}$ Pro for Windows is a product of Borland International)

\subsection{Input Data}

Each model assumes a fuel water pocket, or water in a pore, is at the drying system operating temperature such that saturated steam at the water interface characterizes the driving force for flow, or the concentration driving force for mass transfer. The diffusion analysis assumes helium is recirculated through the $\mathrm{MCO}$ at a rate sufficient to maintain a negligible water concentration in the bulk gas flow. Stagnant helium reduces the water diffusion rate estimated by these calculation, as the mass concentration profile is changed.

The source of modeling equations, describing fluid flow and mass diffusion, is Perry and Chilton (1973). Levenspiel (1984) is used as a check of the modeling equation forms. Parameter values for saturated steam were obtained from steam tables and other parameters derived from handbooks and characterization data.

Table 4-1 provides a summary of key assumptions and parameters used in the analysis of the drying test models. In addition, a list of the conservatism factors included in the alternative test/operating procedures is provided: 
Table 4-1. Key Assumption/Parameter Description

\begin{tabular}{|c|c|c|c|}
\hline & Orifice Flow Model & Porous Bed Flow Model & Diffusion Model \\
\hline Basic Model & $\begin{array}{l}\text { Clad defects modeled as a number of } \\
\text { constant diameter circular orifices with } \\
\text { spherical water pocket behind defect. The } \\
\text { number of water pockets/defects is indicated } \\
\text { by the pressure rise test criterion. }\end{array}$ & $\begin{array}{l}\text { Fuel pores or cracks of arbitrary cross section are modeled } \\
\text { as filled with oxide particles. The flow path length increases } \\
\text { as the pore dries and the liquid interface recedes into the } \\
\text { pore. }\end{array}$ & $\begin{array}{l}\text { Fuel pores or cracks of arbitrary cross section are } \\
\text { modeled as filled with water. The diffusion path } \\
\text { length increases as the liquid interface recedes into } \\
\text { the pore. }\end{array}$ \\
\hline Driving Force & $\begin{array}{l}\text { Saturated steam at fuel temperature inside } \\
\text { the water pocket, critical flow through the } \\
\text { clad defect. }\end{array}$ & $\begin{array}{l}\text { Saturated steam at fuel temperature at the liquid interface } \\
\text { that is receding into the pore or crack. }\end{array}$ & $\begin{array}{l}\text { Saturated steam at the fuel temperature and the total } \\
\text { MCO pressure defines the concentration of water at } \\
\text { the liquid interface that is rececting into the pore. A } \\
\text { bulk gas water vapor concentration completes the } \\
\text { definition of the mass transfer driving force. }\end{array}$ \\
\hline $\begin{array}{l}\text { Key } \\
\text { Configuration } \\
\text { Assumption }\end{array}$ & $\begin{array}{l}\text { A maximum water pocket to defect diameter } \\
\text { ratio of } 200 \text { conservatively describes water } \\
\text { pockets. This is justified by noting the } \\
\text { formation of the maximum single water } \\
\text { pocket requires removal of } 400 \mathrm{~cm}^{3} \text { of oxide } \\
\text { through a defect that is } 0.3 \mathrm{~mm} \text { in diameter } \\
\text { to create a pocket volume of } 200 \mathrm{~cm}^{3} \text {. } \\
\text { Creation of the water pocket by a larger } \\
\text { defect would fail the pressure rise criterion. } \\
\text { Incomplete oxide removal results in retaining } \\
\text { less than } 200 \mathrm{~g} \text { water in the pocket. The } \\
\text { water pocket to defect diameter ratio } \\
\text { satisfying the } 200 \mathrm{~g} \text { limit increases as the } \\
\text { assumed defect diameter decreases. } \\
\text { Therefore, the diameter ratio from a single } \\
\text { water pocket in an MCO is used as a } \\
\text { bounding description of the relative size for } \\
\text { water pockets behind cladding defects. }\end{array}$ & $\begin{array}{l}\text { The total volume of pores/cracks is defined by the bounding } \\
\text { estimate of fuel particulate on fuel elements. The bounding } \\
\text { estimate of fuel in a scrap basket was neglected in defining } \\
\text { the total pore volume based on the test conditions selected } \\
\text { being suitable for completely drying pores that are } 3 \mathrm{~cm} \text { to } 4 \\
\mathrm{~cm} \text { long. Scrap pieces are projected to be primarily } 7.6 \mathrm{~cm} \\
\text { ( } 3 \text { in) or shorter. Therefore, pores/cracks in scrap will not be } \\
\text { a significant contributor to the residual water content. } \\
\text { A predominant pore/crack length of } 5 \mathrm{~cm} \text { was assumed to } \\
\text { describe the total volume described above. This length is } \\
\text { based on visual observations. Actual fuel will have shorter } \\
\text { and longer cracks, with many defined by the fuel wall } \\
\text { thickness of } 1 \mathrm{~cm} \text {. A simplified distribution was investigated } \\
\text { assuming } 25 \% \text { of the total crack volume as } 3 \mathrm{~cm} \text { long } \\
\text { cracks, } 50 \% \text { as } 5 \mathrm{~cm} \text { long, and } 25 \% \text { as } 10 \mathrm{~cm} \text { long. This } \\
\text { yields results similar to the constant } 5 \mathrm{~cm} \text { length model. }\end{array}$ & $\begin{array}{l}\text { The total volume of pores/cracks is defined by the } \\
\text { total volume, particulate density and bed voidage } \\
\text { used in the porous bed flow model. This results in a } \\
\text { void crack volume that is consistent with the voidage } \\
\text { used in the porous bed flow model (i.e., the quantity } \\
\text { of residual water in cracks at the start of drying is the } \\
\text { same for both porous bed flow and diffusion models). } \\
\text { The basis for considering scrap particulate and the } \\
\text { analysis of total crack length is the same as for the } \\
\text { porous bed flow model. }\end{array}$ \\
\hline $\begin{array}{l}\text { Other } \\
\text { Parameters }\end{array}$ & Handbook values. & $\begin{array}{l}\text { Handbook values. } \\
\text { Particle shape factor, density, and diameter in porous bed } \\
\text { from canister sludge characterization data. } \\
\text { Bed voidage based on analysis that maximizes residual water } \\
\text { at the conditions of interest. }\end{array}$ & $\begin{array}{l}\text { Handbook values. } \\
\text { Diffusivity of water vapor in helium from standard } \\
\text { Lennard-Jones parameters. }\end{array}$ \\
\hline
\end{tabular}


Table 4-1. Key Assumption/Parameter Description

\begin{tabular}{|c|c|c|c|}
\hline & Orifice Flow Model & Porous Bed Flow Mociel & Diffusion Model \\
\hline Conservatism & $\begin{array}{l}\text { 1. No pockets similar to this configuration } \\
\text { have been reported in fuel examinations } \\
\text { completed to date. } \\
\text { 2. The mass rate derived from pressure rise } \\
\text { data assume a gas volume equivalent to an } \\
\text { empty MCO. This over predicts the mass } \\
\text { rate by a factor of about } 2 \text {. } \\
\text { 3. Calculation basis assumes fuel } \\
\text { temperature at } 40^{\circ} \mathrm{C} \text {. This underestimates } \\
\text { driving force by } 30 \% \text { if actual fuel } \\
\text { temperature is } 5^{\circ} \mathrm{C} \text { higher. }\end{array}$ & $\begin{array}{l}\text { 1. Bounding fuel particulate used to define total crack } \\
\text { volume. Result is equivalent to } 26 \mathrm{cracks} \text { that are } 0.01 \mathrm{~cm} \\
\text { thick, } 1 \mathrm{~cm} \text { wide, and } 5 \mathrm{~cm} \text { long on both ends of every inner } \\
\text { and outer element placed in a full Mk IV MCO. } \\
2 \text {. Calculation basis assumes fuel temperature at } 40^{\circ} \mathrm{C} \text {. } \\
\text { This underestimates the driving force such that the residual } \\
\text { water estimate for a given time would be about } 30 \% \text { lower if } \\
\text { the actual fuel temperature is } 5^{\circ} \mathrm{C} \text { higher. } \\
3 \text {. Selected residence time provides residual water estimate } \\
\text { that is factor } 2 \text { less than the } 200 \mathrm{~g} \text { criterion for the crack } \\
\text { distribution considered and factor of } 10 \text { below criterion if } \\
\text { assume constant } 5 \mathrm{~cm} \text { long cracks. }\end{array}$ & $\begin{array}{l}\text { 1. Crack definition same as for porous bed flow } \\
\text { model. } \\
2 \text {. Calculation basis assumes fuel temperature at } \\
65^{\circ} \mathrm{C} \text {. This underestimates driving force such that } \\
\text { the residual water estimate for a given residence time } \\
\text { would be } 15 \text { to } 20 \% \text { lower if the actual fuel } \\
\text { temperature is } 5^{\circ} \mathrm{C} \text { higher. } \\
3 \text {. Selected residence time provldes residual water } \\
\text { estimate that is } 30 \% \text { less than the } 200 \mathrm{~g} \text { criterion for } \\
\text { the crack distribution considered and factor of } 4 \\
\text { below criterion if assume constant } 5 \mathrm{~cm} \text { long cracks. }\end{array}$ \\
\hline
\end{tabular}




$$
\text { HNF-1851, Rev } 0
$$

\subsection{CaTculation}

The fuel crevice models depicted in Figure 5-1 indicate water pockets constrained in different configurations. The intent of the calculation is not to predict the actual number and types of crevices in fuel pieces or assemblies that may exist in a particular MCO. The calculation approach is to hypothesize a number of different models that may represent how free water could be constrained. Each model configuration is then used to define a residual free water test, and a conservativé composite of tests used as a basis for residual free water estimates.

Bounding estimates, or configurations of the MCO contents and of pocket and pore sizes and quantities, as defined below, were used to represent how free water could be constrained and detected.

Pockets (Figure 5.1.A)--A smal1 clad defect (18 microns) with a relatively large pocket diameter (slightly less than $1 \mathrm{~cm}$ ) was chosen. Note that the wall thickness of an individual element is approximately 1 $\mathrm{cm}$. Approximately 380 water pockets like this would be required to contain $200 \mathrm{~g}$ of water.

Pores (Figure 5.1.B\&C)--A base crack size of $5 \mathrm{~cm}$ long, $1 \mathrm{~cm}$ wide, and $0.01 \mathrm{~cm}$ thick was selected. The total pore volume utilized would require 28,000 cracks of this size. It is possible to have an individual crack longer than $5 \mathrm{~cm}$, but the total crack length used here is considered bounding. Analysis of a simple distribution where $25 \%$ of the cracks are $3 \mathrm{~cm}$ long, $50 \%$ are $5 \mathrm{~cm}$ long, and $25 \%$ are $10 \mathrm{~cm}$ long produced results similar to assuming all cracks are $5 \mathrm{~cm}$ long.

Fuel/scrap basket contents--A nominal Mark IV MCO contains 4 fuel baskets with 216 total fuel assemblies and 1 scrap basket. The scrap basket has a criticality weight limit of $930 \mathrm{~kg}$, or the weight equivalent of approximately 37 fuel assemblies. An alternate configuration would be 5 fuel baskets with 270 fuel assemblies. Assuming 270 total equivalent fuel assemblies, for the pocket configuration, more than one pocket per fuel assembly would be required. For pores, 26 cracks on both ends of all inners and outers would be required. For both basins, approximately $68 \%$ of the combined inner/outers are defined as intact, with no evidence of cladding breach, Sloughter, et. al., 1997. 
Figure 5-1. Alternative models describing free water drying.

A) Orifice flow model of drying a water pocket beneath a cladding defect

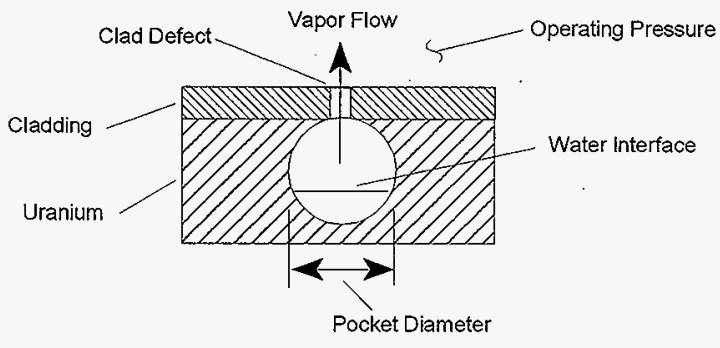

B) Granular bed flow model of drying a water filled pore or crack

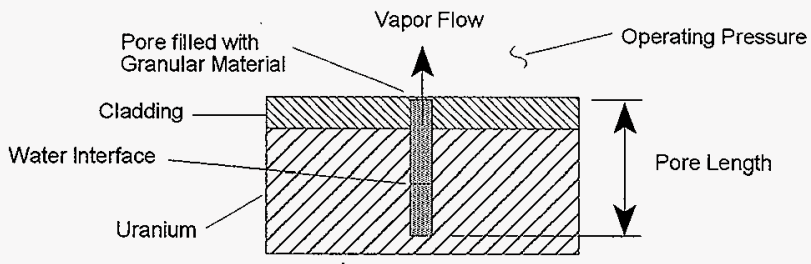

C) Diffusion model of helium recycle drying of a water filled pore or crack

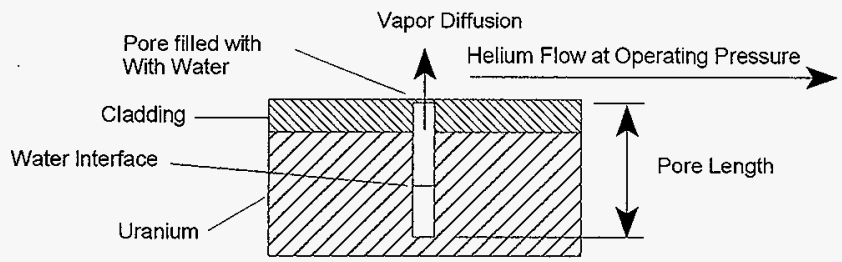


The modeling equations for each model are developed in the Appendices (Sections 9.1 to 9.3). Each model develops an equation estimating the time to dry a characteristic size of fuel crevice and quantity of residual water in an MCO associated with test conditions. A spreadsheet was used to vary parameters and the results plotted in a graphical format. Test calculations are presented for each model and compared with the spreadsheet calcuiation. For models of pore drying, a pseudo-steady state analysis was used to model the transient variation of the flow path Tength, or diffusion path length, projected to occur as the water interface recedes into a pore.

\subsection{Results}

Table 6-1 indicates the results of flow model analyses developed in Sections 9.1, 9.2, and 9.3. The results are presented in terms of conditions that must be produced to indicate an MCO contains less than $200 \mathrm{~g}$ residual free water. Note that a pressure rise test was found to be applicable for only the orifice flow mode1. Definition of the total residual water inventory in the other two models required assuming a pore or crack length that characterizes fuel in an MCO. In these two models, the water interface recedes into the pore, increasing the flow or diffusion path with time. Therefore, a reduced rate of mass flow to the MCO void space is predicted by the pore models, independent of the total remaining water inventory.

Table 6-1. Flow model results

\begin{tabular}{|l|c|c|c|c|}
\hline Test/operating conditions & Orifice flow model & Porous bed flow model & Diffusion model \\
\hline Temperature & $240^{\circ} \mathrm{C}$ & $\geq 40^{\circ} \mathrm{C}$ & $260^{\circ} \mathrm{C}$ & $\leq 65^{\circ} \mathrm{C}$ \\
\hline Pressure & $\leq 30 \mathrm{torr}$ & $\leq 20 \mathrm{tor}$ & $\leq 20 \mathrm{torr}$ & $\leq 000 \mathrm{torr}$ \\
\hline Pressure rise rate & $\leq 3$ torr/hr & $\mathrm{N} / \mathrm{A}$ & $220 \mathrm{hr}$ & $\mathrm{N} / \mathrm{A} / \mathrm{A}$ \\
\hline Test/operating time & $21 \mathrm{hr}$ & $\mathrm{N} / \mathrm{A}$ & $20 \mathrm{hr}$ \\
\hline Helium flow & $\begin{array}{l}\text { Assumes maintaining } \\
\text { partial pressure water } \\
\text { vapor less than } 30 \text { torr }\end{array}$ \\
\hline Results/comments & $\begin{array}{l}\text { Residual water }<200 \mathrm{~g} \text { for } \\
\text { the bounding pocket } \\
\text { definition }\end{array}$ & $\begin{array}{l}\text { Residual water }<200 \mathrm{~g} \text { for } \\
\text { the bounding pore } \\
\text { definition }\end{array}$ & $\begin{array}{l}\text { Residual water }<200 \mathrm{~g} \text { for } \\
\text { the bounding pore } \\
\text { definition }\end{array}$ \\
\hline
\end{tabular}

Each model of mechanisms releasing free water from fuel crevices predicts a mass rate of gas evolved to the MCO void space. Appendix 9.4 investigates the uncertainty in mass rate derived from pressure rise 


$$
\text { HNF-1851, Rev } 0
$$

measurements. Based on reasonable measurement uncertainties, the predicted mass rate is most sensitive to the assumed MCO void volume. The pressure rise criterion presented in this calculation are the most conservative possible, based on an MCO void volume equivalent to an empty MCO. The pressure rise criterion could potentially be raised by close to a factor of two if the MCO void volume were decreased based on a particular fuel loading. However, retaining the current conservative basis provides the most flexibility for the test to accommodate variability in fuel loading, without modifying the test criterion.

Appendix 9.5 investigates the feasibility of using a pressure rise test to verify that thermal stability can be maintained in an MCO when operating at temperatures up to $75^{\circ} \mathrm{C}$. This higher operating temperature was required to produce reasonable operating times for the diffusion model. Table 6-2 provides a summary of pressure rise limits based on alternative mechanisms limiting reaction rates and a pressure rise test temperature of $40^{\circ} \mathrm{C}$. The effective reacting surface area comparison was found to be the mechanism which produces the most restrictive pressure rise test. This was also more restrictive than the test proposed to indicate that the residual water inventory was less than $200 \mathrm{~g}$ by the orifice flow model. Therefore, the pressure rise criterion selected is based on the rate defined by a surface area reaction 7 imitation that allows operation at up to $75^{\circ} \mathrm{C}$.

Table 6-2. Pressure rise limits indicating MCO thermal stability at $75^{\circ} \mathrm{C}$ with helium back fill

\begin{tabular}{|l|c|c|}
\hline \multirow{2}{*}{ Limiting Effect } & \multicolumn{2}{|c|}{ Pressure rise test at $40^{\circ} \mathrm{C}$} \\
\cline { 2 - 3 } & Void $=500 \mathrm{~L}$ & Void $=1000 \mathrm{~L}$ \\
\hline Reacting surface area & 5.2 torr/hr & 2.6 torr/hr \\
\hline Water vapor flow based on orifice flow mode! ${ }^{(1)}$ & 11.8 torr/hr & 5.9 torr/hr \\
\hline Water vapor flow based on porous bed model ${ }^{(2)}$ & $\mathrm{N} / \mathrm{A}$ & $\mathrm{N} / \mathrm{A}$ \\
\hline Water vapor diffusion from pores & 8.6 torr/hr & 4.3 torr $/ \mathrm{hr}$ \\
\hline
\end{tabular}

Notes: (1) Operating pressure with helium must be $<160$ torr for the flow rates predicted by this model to be strictiy applicable. Higher operating pressures with helium at $75^{\circ} \mathrm{C}$ would increase the pressure rise test limit predicted by this model.

(2) N/A - not applicable.

The test/operating procedure for Alternative 1, using the diffusion model, was based on the reacting surface area as the limiting effect assuming a void volume of $1,000 \mathrm{~L}$ for the MCO. This pressure rise criterion is conservative by a factor of 2 based on the void volume selection. In 


$$
\text { HNF-1851, Rev } 0
$$

addition, the reacting surface area analysis assumes all chemical reactions measured by the pressure rise test occur in the scrap basket. Therefore, the pressure rise criterion basis assumes all chemical reaction heat (as indicate by the gas evolved into the MCO void) is concentrated in the scrap basket.

This provides additional conservatism to the conclusion that thermal stability will be maintained at $75^{\circ} \mathrm{C}$, since a portion of the chemical reaction heat will be generated in the fuel baskets.

\subsection{Conclusions}

A pressure rise test on the orifice flow model of fuel crevices is capable of indicating the residual water content of an MCO is below a preselected limit. with reasonable constraints on the conceptual configuration of water pockets constrained by fuel defects. This is not the case for the other two pore models, where the rate of water vapor transmission to the MCO void space decreases with time, independent of the residual water inventory. However, a predominant crack or pore length can be used to define an operating procedure, holding the MCO at a selected set of conditions for a specified time, as a basis for indicating the residual free water inventory is less than $200 \mathrm{~g}$.

\section{8,0 References}

Duncan, D. R., 1997, Spent Nuclear Fuel Project Databook, HNF-SD-SNF-TI-015, Rev 2, DE\&S Hanford, Richland, Washington.

Duncan, D. R., and D. E. Ball, 1997, Therma7 Analysis of Cold Vacuum Drying of Spent Nuclear Fue7, HNF-SD-SNF-CN-023, Rev 0, DE\&S Hanford, Richland, Washington.

Hilsenrath, J., et.al., 1955, Tables of Thermal Properties of Gases, National Bureau of Standard Circular 564, U. S. Department of Commerce, Washington, D. C.

Levenspie1, 0., 1984, Engineering Flow and Heat Exchange, Plenum Press, New York, New York.

Makenas, B. J., 1997, Ana7ysis of S7udge from Hanford K East Basin Canisters, HNF-SP-1201, Rev 0, Duke Engineering \& Services Hanford, Inc., Richland, Washington. 


$$
\text { HNF-1851, Rev } 0
$$

NUMEC, 1963, Progress Report for April 1 through June 30, 1963, Development of Plutonium-Bearing Fuel Materials, P-105, Nuclear Materials and Equipment Corporation, Apollo, Pennsylvania.

Perry, R. H., and C. H. Chilton, 1973, Chemica7 Engineers' Handbook, 5th Edition, McGraw-Hill Book Company, New York, New York.

Sloughter, et.al., 1997, Estimates of Particulate Mass in Multi-Canister Overpacks, HNF-1527, Rev 0, NUMATEC Hanford Corporation, Richland, Washington.

Ritter, et.al., 1997, Hanford Spent Nuclear Fuel Cold Vacuum Drying Proof of Concept Test Report, HNF-SD-SNF-TRP-021, Rev 0, Fluor Daniel Northwest, Richland, Washington. 


$$
\text { HNF-1851, Rev } 0
$$

\subsection{Appendices}

\subsection{Drying Performance using an Orifice Flow Model}

This appendix develops the equations used to describe free water removal from a water pocket constrained by a cladding defect in a fuel element during vacuum drying. This type of model is applicable when the MCO gas pressure is less than about one-half the saturation pressure of water at the fuel temperature. The drying time is characterized by determining the time to remove an equivalent sphere diameter of water through different size cladding defects at various operating conditions [see Figure 5-1(A)]. The c] adding defect is modeled as a square-edged orifice. The pressure difference for flow is defined by assuming saturated steam in the water pocket at the MCO operating temperature. The impact of fuel temperature gradients throughout the MCO is neglected (i.e., all water pockets are assumed to be at a constant temperature).

The orifice flow model can relate a measured pressure rise rate to the number of constant size orifices that may exist in cladding surfaces distributed throughout an MCO. The measured pressure rise, in itself, does not define the potential residual water inventory in pockets behind the defect, as the water pocket volume can be independent of the defect size. The analysis approach investigates the flow and residual water inventory parametrically to determine a practical pressure rise measurement. The ratio of water pocket diameter to defect diameter that satisfies the residual water criterion is then determined. For the test conditions selected, the water pocket diameter can be more than 200 times greater than the cladding defect diameter, while still allowing one to conclude that the residual water inventory in pockets is less than $200 \mathrm{~g}$. 
The flow regimes of interest to define this flow model may range from laminar flow to slip flow to molecular flow, depending on the operating conditions and assumed diameter of a cladding defect. The following equation defines the flow regime (see Equation 5-76 on page 5-29 of Perry and Chilton, 1973).

$$
\begin{aligned}
& x=\frac{\lambda}{d} \sqrt{\frac{8}{\pi}}=\frac{2 \mu}{p_{m}^{\prime} d} \sqrt{\frac{R^{\prime} T}{M g_{0}^{\prime}}} \\
& \text { for laminar flow, } x<0.014 \\
& \text { slip fiow, } 0.014 \leq x \leq 1 \\
& \text { molecular flow, } x>1
\end{aligned}
$$

where: $\lambda=$ mean free path, $f t$

$\mathrm{d}=$ channel diameter, $\mathrm{ft}$

$\mu=$ gas viscosity at $1 \mathrm{~atm}$ and the temperature $\mathrm{T}, \mathrm{lb} / \mathrm{ft}-\mathrm{sec}$

$\mathrm{p}_{\mathrm{m}}^{\prime}=$ arithmetic mean absolute pressure, torr

$\mathrm{R}^{\prime}=$ gas constant, 556 torr $-\mathrm{ft}^{3} / \mathrm{hbmol}-\mathrm{R}$

$T=$ absolute temperature, $R$

$M=$ molecular weight of gas, $18 \mathrm{lb} / \mathrm{bmol}$

$\mathrm{g}_{\mathrm{c}}^{\prime}=$ dimensional constant, $89.6 \mathrm{lb} / \mathrm{ft}-\mathrm{sec}^{2}$-torr

Figure 9.1-1 indicates the flow regimes for an orifice of varying size, assuming the upstream pressure is defined by saturated steam at the operating temperature and an operating pressure of 5 torr. Figure 9.1-2 is an extract of the spreadsheet used to develop Figure 9.1-1.

\subsubsection{Laminar Flow through an Orifice}

Water pocket drying times, assuming the laminar flow regime, are estimated based on the orifice flow equations in Perry and Chitton (1973). For conditions of interest in vacuum drying, the orifice flow is based on critical flow (mass rate dependent only on upstream conditions). Equation 517 in Perry and Chilton (1973) describes the critical flow pressure ratio as follows (see page 5-12 of reference).

$$
r_{0}=\left(\frac{2}{k+1}\right)^{\left(\frac{k}{k-1}\right)}=0.55
$$

where: $r_{c}=$ the pressure ratio, $p_{2} / p_{1}$

$p_{1}, p_{2}=$ upstream and downstream pressures

$k=$ heat capacity ratio, $C_{\nu} / C_{v}=1.3$ for water vapor

Figure 9.1-3 indicates the pressure that must be achieved (or reduced below) during vacuum operations as a function of operating temperature for the drying time estimates generated by this model to be applicable. For example, at an operating temperature of $50^{\circ} \mathrm{C}$, the operating pressure must be less than approximately 45 torr for the flow through defects to be defined by the critical flow equations. 
HNF-1851, Rev 0

Figure 9.1-1. Flow regime variation with defect size and operating temperature for an operating pressure of 5 torr.

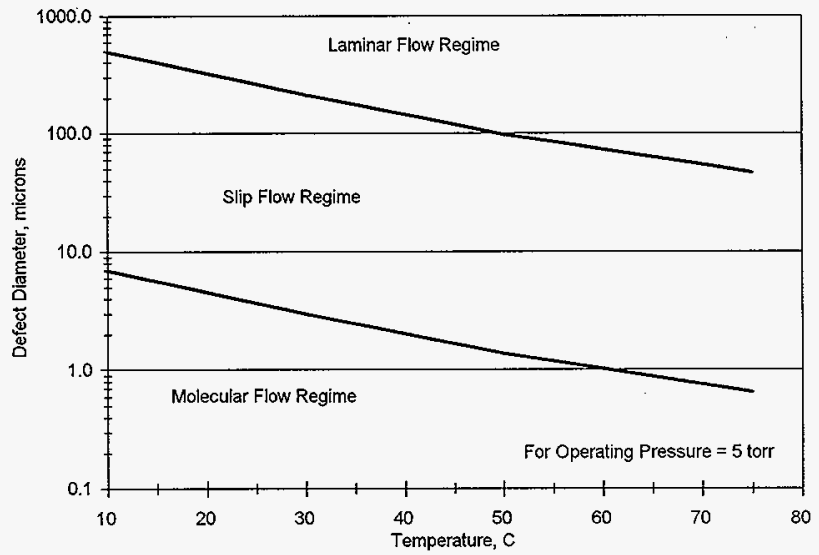

Figure 9.1-2. Spreadsheet calculating flow regimes based on Equation 9.1-1.

\begin{tabular}{|c|c|c|c|c|c|c|c|}
\hline \multicolumn{8}{|c|}{ SLIP FLOW/MOLECULAR FLOW REGION DEFINITION } \\
\hline \multicolumn{8}{|c|}{ From Perry's 5th Equation 5-76 } \\
\hline & \multicolumn{3}{|c|}{$\begin{array}{l}\text { Channel diameters for transition, } \\
\text { micron }\end{array}$} & \multicolumn{3}{|c|}{ Op Press $=5$ torr } & \\
\hline temp, $c$ & $\begin{array}{c}\text { to slip flow } \\
\text { regime }\end{array}$ & $\begin{array}{l}\text { to molecular } \\
\text { flow regime }\end{array}$ & & $\begin{array}{c}\text { Sat press, } \\
\text { torr }\end{array}$ & $\begin{array}{c}\text { mean } \\
\text { pressure, torr }\end{array}$ & $\begin{array}{l}\text { viscosity, } \\
\text { lb/ft-sec }\end{array}$ & temp, $R$ \\
\hline 10 & 496.86 & 6.96 & & 9.20 & 7.10 & 6.11E-06 & 509.4 \\
\hline 30 & 213.61 & 2.99 & & 31.81 & 18.41 & $6.59 \mathrm{E}-0.6$ & 545.4 \\
\hline 50 & 98.48 & 1.38 & & 87.54 & 46.27 & 7.39E-06 & 581.4 \\
\hline 75 & 46.77 & 0.65 & & 289.20 & 147.10 & $1.08 \mathrm{E}-05$ & 626.4 \\
\hline & & & & & & & \\
\hline & & & & $R^{\prime}=$ & 556 & \multicolumn{2}{|c|}{ torr-cu ft/lbmol-R } \\
\hline & & & & $M=$ & 18 & \multicolumn{2}{|l|}{ lb/bmol } \\
\hline & & & & $\mathrm{gc}^{\prime}=$ & 89.6 & \multicolumn{2}{|c|}{ lb/ft-sec^2-torr } \\
\hline
\end{tabular}


Figure 9.1-3. Critical operating pressure for orifice flow in the laminar flow regime.

(Assumes upstream pressure defined by saturated steam)

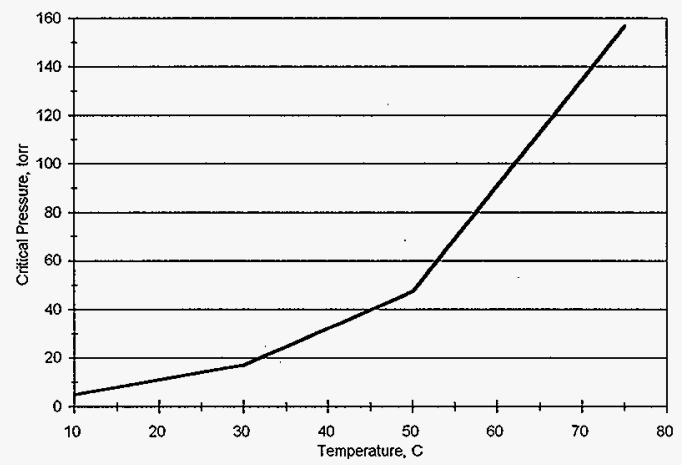

Perry and Chilton (1973) indicate the mass flow through an orifice is defined by the following equation (see Equation 5-18, page 5-12).

$$
w=C A_{2} \sqrt{g_{c} k\left(\frac{p_{1}}{V_{1}}\right)\left(\frac{2}{k+1}\right)^{\frac{(k+1)}{(k-1)}}}
$$

where: $\quad w=$ mass flow rate, $\mathrm{l} b / \mathrm{sec}$

$A_{2}=$ orifice throat area, $\mathrm{ft}^{2}$

$p_{1}=$ upstream pressure, $\mathrm{lbf} / \mathrm{t}^{2}$

$g_{\mathrm{c}}=32.17 \mathrm{lb}-\mathrm{ft} / \mathrm{bf}-\mathrm{sec}^{2}$

$V_{1}=$ upstream specific volume, $\mathrm{ft}^{3} \mathrm{Ab}$

$\mathrm{C}=$ coefficient of discharge

The upstream specific volume, $V_{1}$, can be estimated by the ideal gas 1 aw and substituted into Equation 9.1-3 to yield the following.

$$
w=C A_{2} p_{1} \sqrt{\left(\frac{g_{c} k M}{R T}\right)\left(\frac{2}{k+1}\right)^{\frac{(k+1)}{(k-1)}}}
$$

where: $M=$ molecular weight, $18 \mathrm{lb} / \mathrm{bmol}$

$R=$ gas constant, $1546 \mathrm{ft}-\mathrm{lb}, / \mathrm{bmol}-\mathrm{R}$ 
HNF-1851, Rev 0

This is also equivalent to Equation 3.27 in Levenspiel (1984). To simplify, let

$$
\eta=\frac{g_{c} k M}{R}\left(\frac{2}{k+1}\right)^{\frac{(k+1)}{(k-1)}}
$$

Modeling the cladding defect as a circular orifice yields

$$
A_{2}=\frac{\pi}{4} d^{2}
$$

This results in the mass flow from a single defect modeled as an orifice of

$$
w=C\left(\frac{\pi}{4}\right) d^{2} p_{1} \sqrt{\frac{\eta}{T}}
$$

The pressure rise test yields a measured mass rate, $w_{t}$, from an unknown number of defects. Assuming the defects are all the same diameter, the number of defects that result in the observed measured mass rate during a pressure rise test can be found by the following.

$$
\begin{aligned}
w_{i} & =N w \\
& =N C\left(\frac{\pi}{4}\right) d^{2} p_{1} \sqrt{\frac{\eta}{T}}
\end{aligned}
$$

The maximum defect size possible, while passing the test, is found by setting $\mathrm{N}=1$ in Equation 9.1-6 and solving for $d$.

$$
a_{\max }^{\prime}=\sqrt{\frac{w_{t} \sqrt{T}}{c\left(\frac{\pi}{4}\right) p_{1} \sqrt{n}}}
$$

Figure 9.1-4 indicates the variation of the maximum defect diameter that can exist in a MCO with the mass rate criterion and temperature selected as a basis for the test. 
HNF-1851, Rev 0

Figure 9.1-4. Maximum single defect diameter variation with mass flow rate selected as pressure rise test criterion

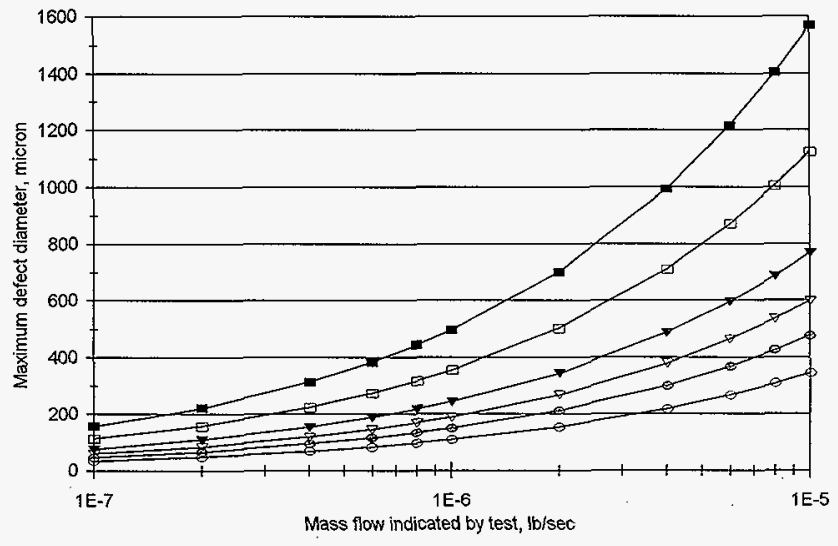

$15 C \square-\square C \rightarrow-40 C-\square-50 C \rightarrow-60 C-0-75 C$

Figure 9.1-5 indicates the spreadsheet calculation used to generate Figure 9.1-4 from Equation 9.1-7. The following example calculation was used to confirm the spreadsheet input. Based on Perry and Chilton (1973), $C=0.75$ at $r=r_{c}$ for sharp edged or square edged orifices (see page 5-14) is used for these calculations. The coefficient of discharge for an orifice actualiy increases to 0.85 as $r$ approaches zero. However, $C=0.75$ is used in this calculation to provide a conservative estimate of mass flow associated with defects. 
HNF-1851, Rev 0

Figure 9.1-5. Spreadsheet calculating maximum defect diameter plotted in Figure 9.1-4 (using Equation 9.1-7)

\begin{tabular}{|c|c|c|c|c|c|c|c|c|}
\hline \multicolumn{9}{|c|}{ Maximum defect diameter variation with selected mass flow rate } \\
\hline & & & & & & & & \\
\hline $\mathrm{gc}=$ & 32.17 & \multicolumn{2}{|c|}{$\mathrm{lb}-\mathrm{ft} / \mathrm{bf}-\sec ^{\wedge} 2$} & $R=$ & 1546 & \multicolumn{3}{|c|}{$\mathrm{ft}-\mathrm{lbff} / \mathrm{bmol}-\mathrm{R}$} \\
\hline$k=$ & 1.3 & & & Eta $=$ & 0.1668 & & & \\
\hline \multirow[t]{9}{*}{$M=$} & 18 & ib/lbmol & & $c=$ & 0.75 & & & \\
\hline & & & & & & & & \\
\hline & & & & & & & & \\
\hline & \multicolumn{8}{|c|}{ Saturated Steam Pressure (from Perry's 5th Ed, Table 3-276) } \\
\hline & \multicolumn{2}{|l|}{ Temperature } & 15 & 25 & 40 & 50 & 60 & 75 \\
\hline & & $\bar{F}$ & 59 & 77 & 104 & 122 & 140 & 167 \\
\hline & & $\mathrm{R}$ & 519 & 537 & 564 & 582 & 600 & 627 \\
\hline & Pressure & P1,psia & 0.2477 & 0.4914 & 1.0758 & 1.7988 & 2.8892 & 5.6172 \\
\hline & & $\mathrm{P} 1, \mathrm{bf} / \mathrm{ft}^{\wedge} 2$ & 35.66 & 70.76 & 154.91 & 259.02 & 416.04 & 808.88 \\
\hline \multirow{4}{*}{$\begin{array}{c}\text { Mass } \\
\text { flow } \\
\text { indicated } \\
\text { by test } \\
\text { lb/sec }\end{array}$} & & & & & & & & \\
\hline & & \multicolumn{7}{|c|}{ Maximum defect diameter at temperature indicated above, $d$ in microns } \\
\hline & & & & & & & & \\
\hline & & & & & & & & \\
\hline $1 \mathrm{E}-07$ & & & 157 & 112 & 77 & 60 & 48 & 35 \\
\hline $2 \mathrm{E}-07$ & & & 222 & 159 & 109 & 85 & 67 & 49 \\
\hline $4 \mathrm{E}-07$ & & & 314 & 225 & 154 & 120 & 95 & 69 \\
\hline $6 \mathrm{E}-07$ & & & 385 & 275 & 188 & 147 & 117 & 85 \\
\hline $8 \mathrm{E}-07$ & & & 444 & 318 & 218 & 170 & 135 & 98 \\
\hline 1E-06 & & & 497 & 356 & 243 & 190 & 151 & 109 \\
\hline $2 E-06$ & & & 702 & 503 & 344 & 268 & 213 & 155 \\
\hline 4E-06 & & & 993 & 711 & 487 & 379 & 302 & 219 \\
\hline $6 \mathrm{E}-06$ & & & 1217 & 871 & 596 & 465 & 369 & 268 \\
\hline $8 E-06$ & & & 1405 & 1006 & 688 & 536 & 427 & 309 \\
\hline 1E-05 & & & 1571 & 1125 & 769 & 600 & 477 & 346 \\
\hline
\end{tabular}

Example calculation:

$$
\begin{array}{ll}
g_{c}=32.171 \mathrm{~b}-\mathrm{ft} / 1 \mathrm{~b}_{\mathrm{f}}-\mathrm{sec}^{2} & \mathrm{R}=1546 \mathrm{ft}-1 \mathrm{~b}_{\mathrm{f}} / 1 \mathrm{bmol}-\mathrm{R} \\
\mathrm{k}=1.3 \text { for steam } & M=18 \mathrm{bb} / 1 \mathrm{bmol} \text { for steam } \\
\mathrm{C}=0.75 &
\end{array}
$$

$$
\eta=\frac{g_{0} k M}{R}\left(\frac{2}{k+1}\right)^{\frac{(k+1)}{(k-1)}}=\frac{(32.17)(1.3)(18)}{(1546)}\left(\frac{2}{1.3+1}\right)^{\frac{(1.3+1)}{(1.3-1)}}=0.1668 \frac{\mathrm{lb}^{2}-R}{\mathrm{Ib}_{f}^{2}-\mathrm{sec}^{2}}
$$

For $T=15^{\circ} \mathrm{C}=519 \mathrm{R}, \mathrm{p}_{1}=0.2477 \mathrm{psia}=35.66 \mathrm{1b} / \mathrm{ft}^{2}$. Then, for $W_{t}=1 \times 10^{-7} \mathrm{lb} / \mathrm{sec}$,

$$
d_{\max }=\sqrt{\frac{w_{t} \sqrt{T}}{C\left(\frac{\pi}{4}\right) \rho_{1} \sqrt{\eta}}}=\sqrt{\frac{\left(1 \times 10^{-7}\right) \sqrt{519}}{(0.75)\left(\frac{\pi}{4}\right)(35.66) \sqrt{0.1668}}}=5.15 \times 10^{-4} f t=157 \text { microns }
$$


HNF-1851, Rev 0

This corresponds to the appropriate spreadsheet entry shown in Figure 9.1-5. The following indicates a units check for Equation 9.1-7.

$$
d_{\max }=\sqrt{\frac{(I b / \mathrm{sec}) \sqrt{R}}{\left(I b / f^{2}\right) \sqrt{\frac{l b^{2}-R}{1 b_{f}^{2}-\sec ^{2}}}}}=\sqrt{\frac{(I b)\left(f^{2}\right) \sqrt{R}\left(\left(b_{f}\right)(\mathrm{sec})\right.}{(\mathrm{sec})\left(I b_{f}\right)(I b) \sqrt{R}}}=f t
$$

The discussion above investigates the largest single defect constraining a water pocket that can exist in an MCO, while passing a specified pressure rise criterion. The pressure rise criterion can also be hypothesized to indicate multiple defects of a smaller size exist in the MCO. This number can be calculated as follows.

$$
N=\frac{w_{t}}{w}=\frac{w_{t} \sqrt{T}}{C\left(\frac{\pi}{4}\right) d^{2} p_{1} \sqrt{\eta}}
$$

Figure 9.1-6 indicates how this number of defects can vary with the defect size and temperature for an example test mass rate criterion of $w_{t}=2 \times 10^{-6} \mathrm{lb} / \mathrm{sec}$.

Figure 9.1-6. Variation in number of defects with defect size and temperature that correspond to a selected pressure rise test criterion

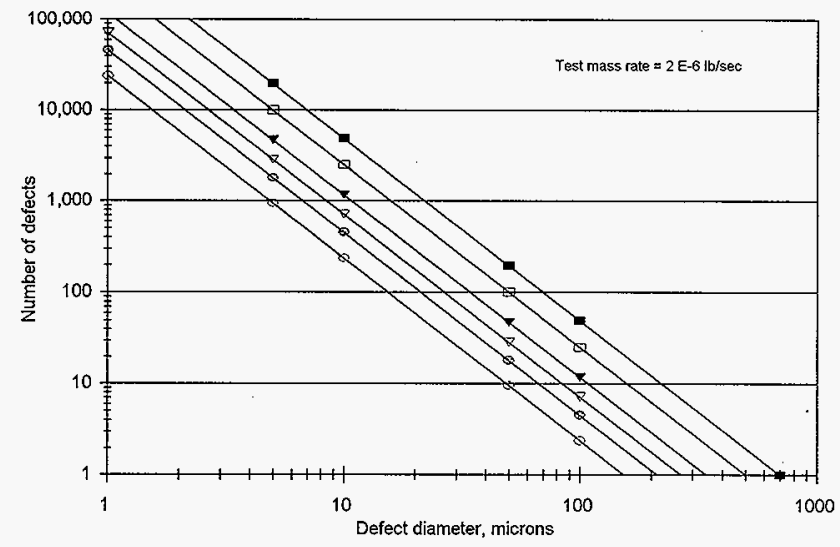

$=-15 \mathrm{C}-25 \mathrm{C} \rightarrow 40 \mathrm{C} \rightarrow 50 \mathrm{C} \rightarrow 60 \mathrm{C} \rightarrow 75 \mathrm{C}$ 
HNF-1851, Rev 0

The mass of residual water in an MCO is estimated by assuming each defect constrains a spherical water pocket of diameter $D$. Therefore, assuming each water pocket is full implies that passing the test results in a residual water mass estimate of:

$$
\begin{aligned}
M_{\mathrm{w}} & =N \rho\left(\frac{\pi}{6}\right) D^{3} \\
& =\frac{w_{t} \sqrt{T} \rho\left(\frac{\pi}{6}\right) D^{3}}{C\left(\frac{\pi}{4}\right) p_{1} \sqrt{\eta} d^{2}} \\
& =\frac{w_{t} \sqrt{T} \rho\left(\frac{2}{3}\right)\left(\frac{D}{d}\right)^{3} d}{C p_{1} \sqrt{\eta}}
\end{aligned}
$$

where: $M_{w}=$ mass residual water in pockets, $\mathrm{lb}$

$\rho=$ density of water, $62.4 \mathrm{lb} / \mathrm{ft} 3$

$\mathrm{D}=$ water pocket diameter, $\mathrm{ft}$

$(D / d)=$ ratio of water pocket diameter to defect diameter

Figure 9.1-7 indicates the variation of the residual water mass with the ratio of the water pocket diameter to defect diameter and defect diameter. The comparison is presented assuming a test criterion mass rate of $2 \times 10^{-6} \mathrm{lb} / \mathrm{sec}$ and a test temperature of $40^{\circ} \mathrm{C}=564 \mathrm{R}$, for example purposes.

This indicates that specifying an observed pressure rise rate will allow projection that the residual water is less than a selected limit if it can be accepted that the water pocket size is related to the defect diameter and the diameter ratio is less than a particular value.

The maximum residual water indicated by a pressure rise test criterion depends on a concept of the maximum ratio of the water pocket diameter to defect diameter (D/d) that can be accepted. This is found for a specified residual water mass criterion as follows.

$$
\begin{aligned}
\left(\frac{D}{d}\right)_{\max } & =\left[\frac{M_{\mathrm{w}, \text { cnit }} C p_{1} \sqrt{\eta}}{\left(\frac{2}{3}\right) w_{t} \sqrt{T} \rho d_{\max }}\right]^{1 / 3} \\
& =\left[\frac{M_{\mathrm{w}, \text { cht }} C p_{1} \sqrt{\eta}}{\left(\frac{2}{3}\right) w_{t} \sqrt{T} \rho\left(\frac{w_{t} \sqrt{T}}{C\left(\frac{\pi}{4}\right) \rho_{1} \sqrt{\eta}}\right)^{1 / 2}}\right]^{1 / 3} \\
& =\frac{M_{\mathrm{w}, \text { chit }}^{1 / 3} C^{1 / 2} \rho_{t}^{1 / 2} \eta^{1 / 2}\left(\frac{3 \sqrt{\pi}}{4}\right)^{2 / 3}}{w_{t}^{1 / 2} \rho^{1 / 3} T^{1 / 2}}
\end{aligned}
$$


HNF-1851, Rev 0

Figure 9.1-7. Variation of residual water in pockets with defect diameter and pocket:defect diameter ratio

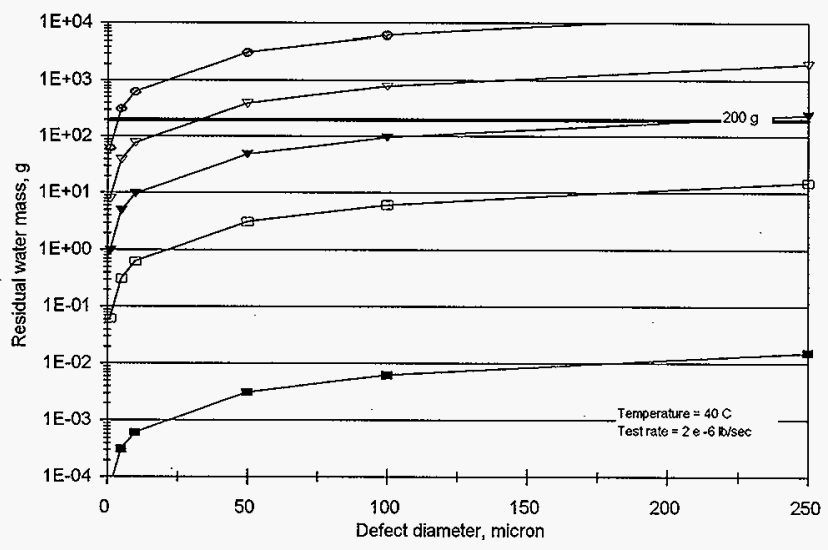

$\rightarrow-(D / d)=10 \quad \square(D / d)=100 \quad \rightarrow(D / d)=250 \quad \rightarrow(D / d)=500 \quad \leftrightarrow(D / d)=1000$ 
HNF-1851, Rev 0

Figure 9.1-8. Variation of maximum acceptable pocket:defect diameter ratio with pressure rise mass rate and temperature for less than $200 \mathrm{~g}$ water

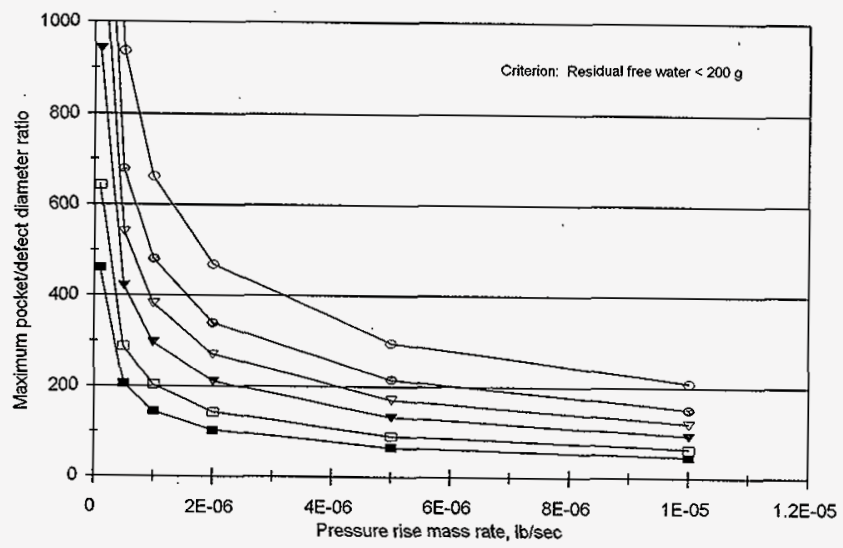

$\rightarrow-15 C-\square-25 C \rightarrow-40 C \rightarrow-50 C \rightarrow 60 C-0-75 C$ 
Equation 9.1-10 can also be used to find the water pocket to defect diameter ratio that must be accepted as a function of the defect diameter for a fixed set of test conditions. As the defect diameter decreases, the ratio that can be accepted to yield a particular residual water inventory increases. Figure 9.1-9 provides an example of this variation for a residual water criterion of $200 \mathrm{~g}$ and measured pressure rise mass rate of $2 \times 10^{-6} 1 \mathrm{~b} / \mathrm{sec}$ at $40^{\circ} \mathrm{C}$.

Figure 9.1-9. Variation of water pocket:defect diameter ratio at fixed test conditions

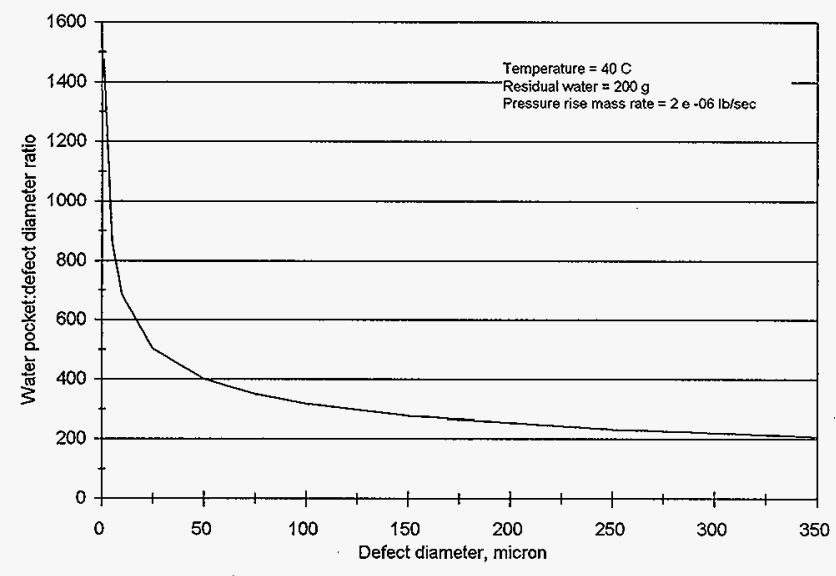

The time to remove water from a spherical pocket of diameter, $D$, in a time period $\tau$, is estimated from the following mass balance.

$$
\text { Mass water removed }=T w=\rho \frac{\pi}{6} D^{3} .
$$

where: $T=$ the time to remove water from a pocket, sec

$\rho=$ density of liquid water, $62.4 \mathrm{lb} / \mathrm{t}^{3}$

$\mathrm{D}=$ diameter of a sphere equivalent to the size of a water pocket, $\mathrm{ft}$ 


$$
\text { HNF-1851, Rev } 0
$$

Substituting Equations 9.1-5 into 9.1-11 and solving for the water pocket diameter yields the following.

$$
\begin{aligned}
D & =\left[\frac{T W}{\rho\left(\frac{\pi}{6}\right)}\right]^{1 / 3} \\
& =\left[\frac{T C\left(\frac{\pi}{4}\right) d^{2} p_{1} \sqrt{\frac{n}{T}}}{\rho\left(\frac{\pi}{6}\right)}\right]^{1 / 3} \\
& =\left[\frac{T C}{\rho}\left(\frac{3}{2}\right) d^{2} p_{1} \sqrt{\frac{n}{T}}\right]^{1 / 3}
\end{aligned}
$$

Figure 9.1-10 provides an indication of the water pocket size expected to be dried during test duration ranging from $1 \mathrm{hr}$ to $3 \mathrm{hr}$ as the constraining defect diameter is varied.

Figure 9.1-10. Variation of pocket size dried during test with defect size and test duration.

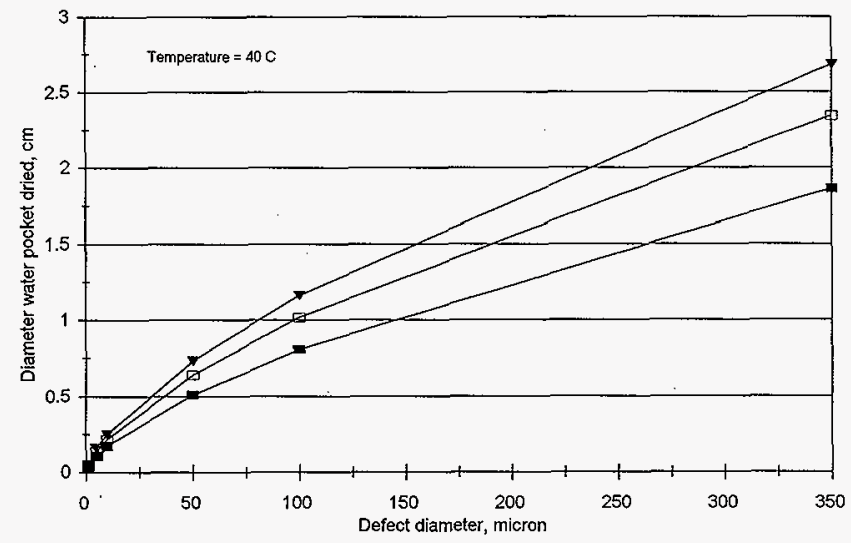

Test duration $=1 \mathrm{hr} \quad-$ Test duration $=2 \mathrm{hr} \quad \forall-$ Test duration $=3 \mathrm{hr}$

\subsubsection{S1 ip Flow through an Orifice}

The relationships modeling slip flow (transition from laminar to molecular flow) were not readily available in Perry and Chilton (1973). Levenspiel (1984) recommends estimating effects in the slip flow regime by adding flow rates calculated based on laminar and molecular flow modeis. This 


$$
\text { HNF-1851, Rev } 0
$$

analysis neglects the molecular flow effect as a conservative model of drying fuel crevices.

\subsubsection{Molecular Flow through an Orifice}

Levenspiel (1984) indicates that laminar flow models underestimate the flow of gases for a specified pressure drop in the molecular flow regime (see Figure 4.8 of reference). Therefore, the simplification in this analysis (neglecting transition to the molecular flow regime) is based on a conservative simplification of flow models by assuming 1 aminar flow for all fuel crevice sizes.

\subsubsection{Pressure Rise Test based on Orifice Mode1}

Based on analysis of the orifice flow model, the following pressure rise test is defined to demonstrate that an MCO contains less than $200 \mathrm{~g}$ of free water in fuel crevices.

\subsubsection{Test temperature}

The test temperature defines the water vapor pressure used as a driving force for flow in the orifice model. Higher temperatures increase the driving force such that:

- the size of a single defect constraining a water pocket associated with a selected pressure rise rate is decreased.

- The number of defects of a particular size associated with a selected pressure rise rate is decreased.

- The water pocket size, relative to the defect diameter, that complies with a residual water 1 imit at a selected pressure rise rate is increased. This is due to the reduced number of defects required to generate a particular pressure rise mass rate in the MCO.

Each of these characteristics indicate higher temperature tests improve the sensitivity of the test for observing the potential existence of water pockets, or strengthens the basis for concluding the free water is within a prescribed limit (e.g., increases the water pocket to defect diameter ratio that can be accepted when passing the test). Therefore, the pressure rise test should be performed at the highest practical temperature for the orifice flow model. 


$$
\text { HNF-1851, Rev } 0
$$

A test temperature criteria of greater than $40^{\circ} \mathrm{C}$ was selected as the basis for the pressure rise test from the orifice flow model calculations. The selection basis is that this temperature represents a conservative approach of fue 1 temperature to the $50^{\circ} \mathrm{C}$ tempered water used for vacuum drying operation.

It is important to note that the fuel is assumed to be at a uniform temperature throughout the test in these calculations. Duncan and Ba11 (1997) indicate that a significant fuel temperature decrease is expected during vacuum drying operations as bulk free water is evaporated from the MCO (see Figures 2.4 and 2.6 of reference for examples). This prediction is supported by cold vacuum drying prototype tests reported in Ritter, et.al. (1997). Therefore, preparations for the pressure rise test must be supported by a step that equalizes fue 1 temperatures. Calculations in Duncan and Ba11 (1997) indicate that fuel basket temperatures can be returned to above $40^{\circ} \mathrm{C}$ by holding the MCO in a stagnant or flowing helium configuration for approximately $4 \mathrm{hr}$ (see Figure 2.3 of reference). Therefore, this preparation must be included in the test procedure for these calculation to be applicable.

\subsubsection{Test Pressure}

Figure 9.1-3 indicates that the MCO must be maintained at a pressure less than approximately 30 torr throughout the test period for the orifice flow model to be applicable when the test temperature is assumed to be $40^{\circ} \mathrm{C}$.

\subsubsection{Test Pressure Rise Rate}

Selection of the test pressure rise rate requires a qualitative assessment of worst case water pockets that could be conservatively encountered in fuel loaded in an MCO. A test pressure rise mass rate criterion of $2 \times 10^{-6} \mathrm{lb} / \mathrm{sec}$, as water vapor, was selected from the orifice flow model analysis at $40^{\circ} \mathrm{C}$ based on Figure 9.1-8. This selection will indicate that the residual water in an MCO is less than $200 \mathrm{~g}$ if the equivalent diameter of a water pocket is no more than 200 times greater than the maximum defect diameter. The selected test criterion would be failed if a single pocket containing water existed in fuel that was constrained by an orifice with diameter greater than 344 micron ( $0.3 \mathrm{~mm}$, see Figure 9.1-4). For the $200 \mathrm{~g}$ residual water mass to be exceeded, this single pocket would be required to contain $200 \mathrm{ml}$ of water, or a volume equivalent to approximately $40 \%$ of an inner fuel element. This was considered conservative because the pocket generation mechanism must involve passing more than $400 \mathrm{ml}$ of oxide corrosion product (minimum volume expansion due to conversion of metal to oxide) through a $0.3 \mathrm{~mm}$ diameter defect without enlarging the hole. A larger 


$$
\text { HNF-1851, Rev } 0
$$

defect would not pass the pressure rise test, while less material passed through the defect would not produce a pocket large enough to contain more than $200 \mathrm{~g}$ of water.

Figure 9.1-9 indicates that the water pocket size, relative to the defect diameter, can increase as the defect diameter decreases and still comply with a selected mass limit. Therefore, the diameter ratio at the maximum defect diameter bounds water pockets behind smalier defects.

Based on the selected mass rate of $2 \times 10^{-6} \mathrm{1b} / \mathrm{sec}$ as water vapor, Figure 9.4-3 indicates an observed pressure rise rate of less than 3 torr $/ \mathrm{hr}$ at $40^{\circ} \mathrm{C}$ will conservatively indicate the MCO residual water content is less than $200 \mathrm{~g}$.

\subsubsection{Test Duration}

The test duration defines a time period where the MCO configuration is controlled at conditions such that the fuel crevice models are applicable. For conservatism, no credit is taken for water removal from crevices prior to the test. In addition, it is unlikely that an argument can be developed to support significant water removal from crevices prior to the test due to the potential for wide variation of fuel temperature within the MCO during vacuum drying and operation at pressures where there is no driving force for crevice water removal.

Figure 9.1-10 indicates the size of water pocket dried by various test durations based on the defect size. The size of water pocket dried during the test increases with test duration for a given defect diameter. However, rearrangement of Equation 9.1-10 to calculate the fraction of water removed with test duration results in an estimate of approximately $2 \%$ per hour for worst case water pocket to defect diameter ratios indicated in Figure 9.1-9. This is calculated as follows, using properties at $40^{\circ} \mathrm{C}$.

$$
\begin{aligned}
\text { Fraction water removed from pockets } & =\frac{w T}{\rho\left(\frac{\pi}{6}\right) D^{3}} \\
& =\frac{C\left(\frac{3}{2}\right) p_{1} \sqrt{\frac{\eta}{T}}}{\rho\left(\frac{D}{d}\right)^{3} d} T \\
& =\frac{(0.75)\left(\frac{3}{2}\right)(154.9) \sqrt{\frac{0.1668}{564}}}{(62.4)\left(200^{3}\right)(0.0011)}(\mathrm{T}, \text { insec }) \\
& =\left(5.5 \times 10^{-6}\right)(\mathrm{T}, \text { insec })=(0.02)(\mathrm{T}, \text { inhr })
\end{aligned}
$$




$$
\text { HNF-1851, Rev } 0
$$

There appears to be no compelling reason to select a particular test duration based on drying fuel pockets.

Section 9.4 discusses uncertainty for the pressure rise measurement.

The measurement uncertainty decreases with longer test durations. Uncertainty in the mass rate measurement is estimated by Equation 9.4-6. The contribution of the test duration and temperature uncertainty to the overall mass rate uncertainty is equal to $(\Delta \tau / \tau)^{2}$ and $(\Delta T / T)^{2}$, respectively. If the temperature uncertainty is $5 \mathrm{~K}$ at $313 \mathrm{~K}\left(40^{\circ} \mathrm{C}\right)$, then $(\Delta \mathrm{T} / \mathrm{T})^{2}=2.5 \times 10^{-4}$. For the contribution of the test duration to the measurement uncertainty to approximately the same as the temperature uncertainty, the test duration, $\tau$, must be greater than $1.04 \mathrm{hr}$, assuming $\Delta \tau$ is $1 \mathrm{~min}$. Therefore, a test duration of greater than $1 \mathrm{hr}$ wi1l not contribute excessive uncertainty to the pressure rise mass rate measurement. 


\subsection{Drying Performance using a Porous Bed Flow Model}

This section develops modeling equations for drying of pores or cracks packed with oxide particles based on flow of water vapor through a porous bed. This type of model is applicable when the MCO gas pressure is less than the saturation pressure of water at the fuel temperature.

The modeling equation development does not result in finding a pressure rise measurement that can show residual free water is less than a particular criterion. However, the porous bed analysis can be used to define an operating procedure (hold MCO fuel at a selected temperature for a time period) that can form the basis for concluding free water has been reduced below a criterion. The flow equations predict the rate that a liquid interface recedes into a fuel crack or pore based on the selected operating conditions (Equation 9.2-10). Based on this relationship, and a total pore or crack length, the residual free water as a function of residence time can be estimated (Equation 9.2-12).

Parameter variations were used to find conditions that can form a basis for concluding free water is less than $200 \mathrm{~g}$. It was found that practical operating times can be achieved at fuel temperatures as $70 \mathrm{w}$ as $40^{\circ} \mathrm{C}$. Higher temperatures reduce the required holding time.

\subsubsection{Compressible Flow through a Porous Bed}

This appendix develops the equation used to describe free water removal from a crack or defect in a fuel element with operating conditions. The fuel defect is modeled as a pore or crack of arbitrary cross section that is packed with a bed of granular particles. An interface of water within the pore is assumed to produce a pressure equal to that of saturated steam as a driving force for flow to the fuel element surface. The pressure difference for flow is defined by assuming steam at the fuel element surface is at the test temperature and pressure. As water evaporates from the pore, the water interface retreats down the pore length until all water is removed. A pseudosteady state analysis is used to estimate the rate that the interface retreats within the pore.

The water vapor flow rate from a water interface in a granular particle filled pore to the fuel element surface is estimated using the flow equation in Perry and Chilton (1973) for a single compressible fluid through a bed of granular solids. The following equation is found as Equation 5-172 of pg 5-53 in the reference. 


$$
\begin{gathered}
\text { HNF-185], Rev } 0 \\
p_{1}^{2}-p_{2}^{2}=\frac{2 Z R G^{2} T}{g_{c} M}\left[\ln \left(\frac{V_{2}}{V_{1}}\right)+\frac{2 f_{m} L(1-\epsilon)^{3-n}}{\phi_{s}^{3-n} e^{3} D_{\rho}}\right]
\end{gathered}
$$

where: $\quad p_{1}, p_{2}=$ upstream and downstream pressure, $\mid b f / f t^{2}$

$Z=$ gas compressibility factor

$\mathrm{R}=$ gas constant, $1546 \mathrm{ft}-\mathrm{lbf} / \mathrm{bmol}-\mathrm{R}$

$T=$ absolute temperature, $R$

$\mathrm{M}=$ gas molecular weight, $\mathrm{lb} / \mathrm{bmol}$

$G=$ fluid superficial mass rate based on empty channel cross section, $\mathrm{lb} / \mathrm{sec}-\mathrm{ft}^{2}$

$g_{\mathrm{c}}=32.17 \mathrm{lb}-\mathrm{ft} / \mathrm{bf}-\mathrm{sec}^{2}$

$V_{1}, V_{2}=$ upstream and downstream gas specific volume, $\mathrm{t}^{3} \mathrm{fb}$

$f_{m}=$ friction factor based on a modified Reynolds Number which is indicated on Figure 5-69 (see pg 5-52) of

Perry and Chilton (1973). That is $f_{m}=F\left(N_{R e}^{\prime}\right)$, where $N_{R e}=D_{p} G / \mu$ and $\mu=$ fluid viscosity in lb/ft-sec.

$L=$ bed, or pore, depth, $\mathrm{ft}$

$D_{p}=$ average equivalent sphere particle diameter, $\mathrm{ft}$

$e=$ bed voidage (fraction free volume), dimensionless

$\mathrm{n}=$ exponent (also a function of $\mathrm{N}_{\mathrm{Re}}$ obtained from Figure 5-69 of Perry and Chilton, 1973).

$\phi_{\mathrm{s}}=$ shape factor from Table 5-22 of Perry and Chilton (1973).

For application in this analysis, Equation 7.2-1 is solved for the superficial mass rate, $G$. This could be considered a trial and error type of problem to solve due to the relationship between $f_{m}$ and $N^{\prime}{ }_{R e}$ and $n$ and $N^{\prime}{ }_{R e}$. However, the solution can be simplified by assuming $N^{\prime}{ }_{R e}<10$ and checking the result. Based of Figure 5-69 in Perry and Chilton (1973), $n=1$ for $N^{\prime}{ }_{R e}<10$. Also, $f_{m}$ is a linear function of $N^{\prime}{ }_{R e}$ on a log-log plot in the laminar flow region $\left(N_{R e}^{\prime}<10\right)$. Therefore, $f_{m}$ can be defined as an explicit function of $N^{\prime}{ }_{R e}$ for the laminar flow region as follows.

From Figure 5-69 of Perry and Chilton (1973), $f_{m}=10$ at $N^{\prime}{ }_{R e}=10$ and $f_{m}$ $=10^{5}$ at $\mathrm{N}_{R e}^{\prime}=10^{-3}$. Assuming the equation form $\log _{10} f_{m}=a+b \log _{10} N_{R e}^{\prime}$ and solving for the constants, $a$ and $b$, yields Equation 9.2-2.

$$
f_{m}=\frac{100}{N_{R \theta}}=\frac{100 \mu}{D_{p} G} \text { for } N_{R e}<10
$$

Equation 9.2-1 can be rearranged to solve for $G$, substituting $n=1$ and Equation 9.2-2. This results in a quadratic equation that can be solved for $G$ which is derived as follows.

$$
\begin{aligned}
\frac{\left(p_{1}^{2}-p_{2}^{2}\right) g_{c} M}{2 Z R T} & =G^{2}\left[\ln \left(\frac{V_{2}}{V_{1}}\right)+\frac{2 f_{m} L(1-\epsilon)^{2}}{\phi_{s}^{2} \epsilon^{3} D_{p}}\right] \\
& =G^{2} \ln \left(\frac{V_{2}}{V_{1}}\right)+G^{2}\left(\frac{100 \mu}{D_{p} G}\right)\left(\frac{2 L(1-\epsilon)^{2}}{\phi_{s}^{2} \epsilon^{3} D_{\rho}}\right)
\end{aligned}
$$

or,

$$
G^{2} \ln \left(\frac{V_{2}}{V_{1}}\right)+G\left(\frac{200 \mu L(1-\mathrm{e})^{2}}{\phi_{s}^{2} \epsilon^{3} D_{\rho}^{2}}\right)-\frac{\left(P_{1}^{2}-P_{2}^{2}\right) g_{c} M}{2 Z R T}=0
$$


Test cases using values modeling parameters of interest for this problem found that the quadratic solution approach yield answers dependent on small differences of large numbers. This is the result of

$$
G^{2} \ln \left(\frac{V_{2}}{V_{1}}\right) \lll G\left(\frac{200 \mu L(1-\epsilon)^{2}}{\phi_{s}^{2} e^{3} D_{\rho}^{2}}\right)
$$

Based on a similar development in Levenspiel (1984), the relationship in Equation 9.2-5 is equivalent to neglecting turbulent friction losses, which is considered reasonable in the laminar flow regime. Therefore,

$$
G\left(\frac{200 \mu L(1-\epsilon)^{2}}{\phi_{s}^{2} \epsilon^{3} D_{p}^{2}}\right) \approx \frac{\left(p_{1}^{2}-p_{2}^{2}\right) g_{c} M}{2 Z R T}
$$

or

$$
G \approx \frac{\left(p_{1}^{2}-p_{2}^{2}\right) g_{c} M \phi_{s}^{2} \epsilon^{3} D_{p}^{2}}{400 Z R T \mu L(1-\epsilon)^{2}}
$$

The superficial mass flow rate through the pore is a function of the granular bed length. Therefore, as the water interface recedes into the pore, the mass flow rate decreases. The time to empty the pore volume of water can be estimated by a pseudo steady state evaluation. This method determines the time increment for increasing the flow path by a length increment and integrates over the total pore length. For an arbitrary pore cross sectional area, $A_{x}$, the following equations describe the pseudo steady state analysis.

Water mass in a length increment $=\left(A_{x}, f t^{2}\right) \in\left(\rho, l b / t^{3}\right)(\Delta z, f t)$

$$
=A_{x} \in \rho(\Delta z), I b
$$

Water mass removed in a time increment $=\left(A_{x}, f^{2}\right)\left(G, 1 b / s e c-f t^{2}\right)(\Delta t$, sec $)$

$$
=A_{x} G(\Delta t), i b
$$

where $\rho$ is the density of liquid water. This results in

$$
\begin{aligned}
A_{x} G(\Delta t) & =A_{x} \in \rho(\Delta z), \text { or } \\
\frac{d z}{d t} & =\frac{G}{\epsilon \rho}, \text { as } \Delta z, \Delta t \text { approach } 0
\end{aligned}
$$

Let

$$
\alpha=\frac{\left(p_{1}^{2}-p_{2}^{2}\right) g_{c} M \phi_{s}^{2} \epsilon^{3} D_{p}^{2}}{400 Z R T \mu(1-\varepsilon)^{2}}, \text { such that } G=\frac{\alpha}{L}
$$

then

$$
\frac{d z}{d t}=\frac{\alpha}{\epsilon \rho z}
$$


Solving this yields

$$
\begin{aligned}
\int_{0}^{L} z d z & =\frac{\alpha}{\epsilon \rho} \int_{0}^{\gamma} d t \\
\frac{L^{2}}{2} & =\frac{\alpha T}{\epsilon \rho} \\
T & =\frac{\varepsilon \rho L^{2}}{2 \alpha}
\end{aligned}
$$

Alternatively, the length of bed dried in a particular time can be found by rearranging Equation 9.2-9 to the following.

$$
\begin{aligned}
L & =\sqrt{\frac{2 \alpha T}{\epsilon \rho}} \\
& =\frac{\phi_{s} \in D_{p}}{(1-\epsilon)} \sqrt{\frac{\left(p_{1}^{2}-p_{2}^{2}\right) g_{c} M T}{200 \rho Z R T \mu}}
\end{aligned}
$$

A total length of pore or crack characteristic of cross-sectional area must be defined in order to estimate the residual water remaining in an MCO from this model. For simplicity, all pores and cracks are assumed to be the same Tength, such that the total volume of porous beds is equivalent to $\left(A_{x}\right) \times$ $\left(L_{\text {tot }}\right)$. This total volume of porous beds can be related to the mass of particulate estimated to be in fuel by the following equation.

$$
A_{x} L_{\text {tot }}=\frac{M_{\rho}}{(1-\varepsilon) \rho_{\rho}}
$$

where: $\quad M_{\rho}=$ mass of particulate in fuel pores, ib

$\rho_{\mathrm{p}}=$ particle density of particulate in fuel pores, $\mathrm{lb} / \mathrm{t}^{3}$

The residual water in pore voids is found from the difference between the total pore or crack length and the length of pore dried during the test. Substituting Equation 9.2-11 into the description of the mass of residual water results in the following equation.

$$
\begin{aligned}
M_{\mathrm{w}} & =\epsilon \rho A_{x}\left(L_{\text {tot }}-L\right) \\
& =\left(\frac{\epsilon}{1-\epsilon}\right)\left(\frac{\rho}{\rho_{p}}\right) M_{\rho}\left(1-\frac{L}{L_{\text {tot }}}\right)
\end{aligned}
$$

where: $\quad M_{w}=$ mass of residual water in $M C O$, ib

The mass rate of vapor entering the MCO void space, assuming this type of model, continually decreases as the interface retreats into the porous bed. Therefore, the mass rate measured by a pressure rise test is equivalent to the total mass of water removed from pores over the test duration. This results in the following estimate for the measured mass rate. 


$$
\begin{aligned}
\text { HNF }-1851, \operatorname{Rev} 0 \\
W_{t}=\frac{A_{x} \epsilon \rho L}{T} \\
=\left(\frac{\epsilon}{1-\epsilon}\right)\left(\frac{\rho}{\rho_{p}}\right)\left(\frac{M_{p}}{\mathrm{~T}}\right)\left(\frac{L}{L_{t \alpha}}\right)
\end{aligned}
$$

Equations 9.2-10,9.2-12, and 9.2-13 form the design equation describing the pressure rise test in terms of the porous bed mode1. The modeling equations relate the residual water content to the porous bed properties, total length of pores, time duration of the test, test operating pressure and temperature dependent properties of the fluid (steam).

\subsubsection{Porous Bed Properties and Parametric Variation}

The following discussion describes the basis for porous bed properties used in this calculation.

$\Phi_{s}=$ shape factor $=0.6$

Table 5-22 of Perry and Chilton (1973) lists shape factors for a variety of non-spherical particles ranging from 0.2 for wire spirals to 0.95 for ottawa sand (nearly spherical grains). Makenas (1997) lists shape factor measurements from four $K$ East Basin canister sludge samples ranging from 0.58 to 0.66 (see Table I.7.1 of reference). Therefore, a shape factor of 0.6 was used for the porous bed flow model calculations.

$D_{p}=$ average equivalent particle diameter $=4.9 \times 10^{-5} \mathrm{ft}$

Makenas (1997) reports the results of particle size distribution measurements. Coarse sorting measurements indicate $56 \%$ to $98 \%$ of particles have diameters less than 710 micron (see Table I.6.1-2 of reference). Mean sizes for the smaller particles are reported on both a particle number and particle volume weighted basis (see Table I.6.1-3 of reference). Levenspiel (1984) indicates that the average equivalent particle diameter of interest in the porous bed flow equations is based on a mass weighted average, which is equivalent to the volume weighted average diameter assuming a constant particle density.

The volume weighted mean diameter of particles reported by Makenas (1997) range from 16.3 to $321 \mathrm{micron}$ for as received samples. Smaller mean particle sizes, ranging from 10 to 227 microns, are reported for samples after treatment by ultrasonification. Based on these data, an average equivalent 
particle diameter of 15 microns, or $4.9 \times 10^{-5} \mathrm{ft}$, is used to characterize the porous bed in these calculations.

$e=$ voidage $=0.6, \rho_{p}=$ particle density $=7.9 \mathrm{~g} / \mathrm{cm}^{3}=4931 \mathrm{~b} / \mathrm{ft}^{3}$

The predicted flow rate from a porous bed are sensitive to the bed voidage estimate. Bed voidage in an MCO pore or crack can vary based on how the material was formed. In some cases, the pore could be filled with oxidation product that is compressed within the fuel metal resulting in a low bed voidage. Other configurations could be the result of deposits that formed particulate in another location that settled into a crack, resulting in a high bed voidage.

Makenas (1997) reports a wide range of measured sludge densities form $K$ East Basin canister sludge samples (see Table I.8-1 of reference. Settled sludge densities range from 1 to $2.5 \mathrm{~g} / \mathrm{m} 7$, centrifuged sludge densities range from 1.2 to $4.5 \mathrm{~g} / \mathrm{ml}$, and dried solids densities range from 3.5 to $7.9 \mathrm{~g} / \mathrm{ml}$. Data from fuel fabrication experiments indicate that uranium dioxide powder densities of 4.7 to $5.3 \mathrm{~g} / \mathrm{ml}$ can be achieved when compacted to 10 tons $/ \mathrm{in}^{2}$ (NUMEC, 1963). Assuming a theoretical density for particulate in pores equivalent to that of uranium dioxide $(10.97 \mathrm{~g} / \mathrm{ml})$, the following range of bed voidage estimates would be predicted from the various density data.

$$
\begin{aligned}
\rho_{\text {bulk }} & =(1-\epsilon) \rho_{\text {thoory }} \\
\epsilon & =\frac{\rho_{\text {thoory }}-\rho_{\text {bulk }}}{\rho_{\text {theory }}} \\
& =\frac{10.97-[1 \text { to } 7.97]}{10.97}=0.27 \text { to } 0.91
\end{aligned}
$$

Due to this wide range, the residual water design equation was investigated to determine the voidage that yields the maximum residual water estimate.

Combining Equation 9.2-12 and 9.2-10 yields the following relationship for the residual water in an $\mathrm{MCO}$.

$$
M_{\mathrm{w}}=\left(\frac{\epsilon}{1-\epsilon}\right)\left(\frac{\rho}{\rho_{\rho}}\right) M_{\rho}\left[1-\left(\frac{\epsilon}{1-\epsilon}\right)\left(\frac{\phi_{s} D_{p}}{L_{t \alpha}}\right) \sqrt{\left.\frac{\left(p_{1}^{2}-p_{2}^{2}\right) g_{c} M_{\mathrm{T}}}{200 \rho Z R T \mu}\right]}\right.
$$

This can be simplified to a function with respect to the voidage while treating all other parameters as constants. 


$$
\begin{gathered}
\text { HNF-1851, Rev } 0 \\
f(\epsilon)=\frac{M_{\mathrm{w}}}{\left(\frac{\rho}{\rho_{p}}\right) M_{\rho}}=\left(\frac{\epsilon}{1-\epsilon}\right)-a\left(\frac{\epsilon}{1-\epsilon}\right)^{2} \\
\text { where: } a=\left(\frac{\phi_{s} D_{p}}{L_{\text {tot }}}\right) \sqrt{\frac{\left(\rho_{1}^{2}-p_{2}^{2}\right) g_{\mathrm{e}} M T}{200 \rho Z R T \mu}}
\end{gathered}
$$

This can be differentiated with respect to the voidage to find the point of maximum residual water content.

$$
\frac{d f}{d \epsilon}=\left(\frac{1}{(1-\varepsilon)}+\frac{\varepsilon}{(1-\epsilon)^{2}}\right)\left(1-2 a \frac{\varepsilon}{(1-\varepsilon)}\right)
$$

Setting the derivative to zero finds the voidage where the residual water content is a maximum. Noting that the voidage is between 0 and 1 , the first term of the derivative can not be zero. Therefore, the residual water estimate is maximum for the following voidage.

$$
\begin{aligned}
{\left[1-2 a \frac{\epsilon}{(1-\epsilon)}\right] } & =0, \text { or } \\
\epsilon & =\frac{1}{2 a+1}
\end{aligned}
$$

Figure 9.2-1 indicates the variation of the voidage that results in a maximum residual water estimate with temperature, assumed total pore length, and test residence time. Figure 9.2-2 provides a copy of the spreadsheet calculation used to create Figure 9.2-1. Figure 9.2-1 indicates that the voidage for maximum residual water decreases as the temperature increases or total pore length decreases. This relationship results from a balance between increased superficial mass flow rates and increased water mass per unit volume of pore that must be removed as the bed voidage is increased. Comparison of Figures 9.2-1(a) and 9.2-1(b) indicate that longer test residence times will decrease the voidage predicted for maximum residual water.

A bed voidage estimate of 0.6 is used for these calculations based on the temperature range of interest of $40^{\circ} \mathrm{C}$ to $60^{\circ} \mathrm{C}$. Figure $9.2-1$ indicates that conditions can be hypothesized where higher voidage estimates would produce larger residual water estimates. However, this results in a looser packing that would be unlikely to be observed in long cracks or pores. 


$$
\text { HNF-1851, Rev } 0
$$

Figure 9.2-1. Variation of voidage for maximum residual water with temperature and total pore length

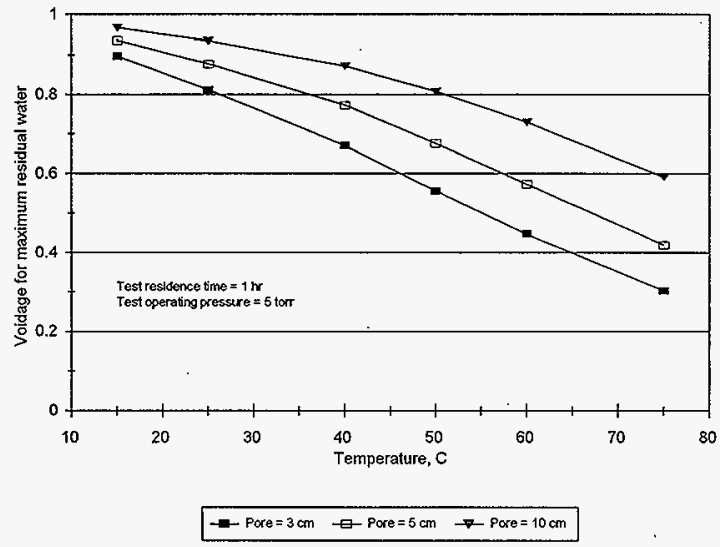

a) Test residence time $=1 \mathrm{hr}$

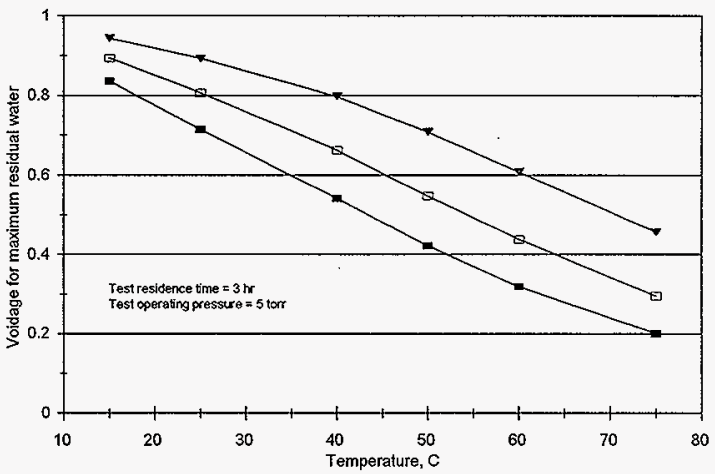

$\rightarrow-$ POre $=3 \mathrm{~cm} \quad \square-$ Pore $=5 \mathrm{~cm} \quad \nabla$ Pore $=10 \mathrm{~cm}$

b) Test residence time $=3 \mathrm{hr}$ 


$$
\text { HNF-1851, Rev } 0
$$

Figure 9.2-2. Spreadsheet calculating void volume for maximum residual water based on Equation 9.2-15

\begin{tabular}{|c|c|c|c|c|c|c|c|}
\hline \multicolumn{8}{|c|}{ Variation of void volume for maximum residual water with parameters } \\
\hline \multicolumn{8}{|c|}{ - Parameters to vary are temperature, residence time, and assumed maximum pore length - } \\
\hline $\mathrm{gc}=$ & 32.17 & \multicolumn{2}{|c|}{$\mathrm{lb}-\mathrm{ft} / \mathrm{bf}-\sec ^{\wedge} 2$} & $D p=$ & \multicolumn{2}{|r|}{$4.921 \mathrm{E}-05 \mathrm{ft}$} & \\
\hline$M=$ & 18 & lb/bmol & & $Z=$ & 1 & & \\
\hline phi $=$ & 0.6 & & & $R=$ & 1546 & \multicolumn{2}{|l|}{ ft-lbf/lbmol-R } \\
\hline \multicolumn{2}{|c|}{ Operating pressure $=$} & 5 & torr $=$ & 13.93 & $\mathrm{Ibffft} 2$ & & \\
\hline \multicolumn{8}{|c|}{ Saturated Steam Pressure (from Perry's 5th) and viscosity (From Hilsenrath, et. al., 1955, Table 9.6) } \\
\hline \multirow[t]{3}{*}{ Temp } & $\mathrm{C}$ & 15 & 25 & 40 & 50 & 60 & 75 \\
\hline & $K$ & 288 & 298 & 313 & 323 & 333 & 348 \\
\hline & $\mathrm{R}$ & 519 & 537 & 564 & 582 & 600 & 627 \\
\hline Pressure & $P 1, \mathrm{lbf} / \mathrm{sq} \mathrm{ft}$ & 35.66 & 70.76 & 154.91 & 259.02 & 416.04 & 808.88 \\
\hline Viscosity & $\mathrm{lb} / \mathrm{ft}-\mathrm{sec}$ & $6.302 E-06$ & $6.544 \mathrm{E}-06$ & $6.907 E-06$ & $7.148 \mathrm{E}-06$ & 7.39E-06 & $7.756 \mathrm{E}-06$ \\
\hline \multicolumn{2}{|c|}{ Residence time $=$} & 1 & $\mathrm{hr}$, or & 3600 & sec & & \\
\hline \multicolumn{2}{|c|}{ Max pore length } & \multicolumn{6}{|c|}{ Constant a in Equation 9.2-14 at temperature indicated above } \\
\hline $\mathrm{cm}$ & ft & \\
\hline 1. & 0.033 & 0.170 & 0.346 & 0.731 & 1.186 & 1.847 & 3.431 \\
\hline 3 & 0.098 & 0.057 & 0.115 & 0.244 & 0.395 & 0.616 & 1.144 \\
\hline 5 & 0.164 & 0.034 & 0.069 & 0.146 & 0.237 & 0.369 & 0.686 \\
\hline 10 & 0.328 & 0.017 & 0.035 & 0.073 & 0.119 & 0.185 & 0.343 \\
\hline & & & & & & & \\
\hline \multicolumn{2}{|c|}{ Maxpore length } & \multicolumn{6}{|c|}{ Voidage for maximum residual water at conditions above } \\
\hline $\mathrm{cm}$ & $\mathrm{ft}$ & & & & & & \\
\hline 1 & 0.033 & 0.75 & 0.59 & 0.41 & 0.30 & 0.21 & 0.13 \\
\hline 3 & 0.098 & 0.90 & 0.81 & 0.67 & 0.56 & 0.45 & 0.30 \\
\hline 5 & 0.164 & 0.94 & 0.88 & 0.77 & 0.68 & 0.58 & 0.42 \\
\hline 10 & 0.328 & 0.97 & 0.94 & 0.87 & 0.81 & 0.73 & 0.59 \\
\hline
\end{tabular}




\section{HNF-1851, Rev 0}

Figure 9.2-3 shows the variation of the residual water estimate for an MCO based on Equations 9.2-10 and 9.2-12 with a constant bed voidage of 0.6. Figure 9.2-4 provides the spreadsheet calculation used to develop the plots in Figure 9.2-3. The total mass of fuel particulate in cracks used to develop Figure $9.2-4$ is $4.32 \mathrm{~kg}$ based on the bounding estimate of particulate on fuel in Sloughter, et.al. (1997). The particulate density of $7.9 \mathrm{~g} / \mathrm{ml}$ used for estimating the drying of fuel cracks is the maximum particle density reported in Makenas (1997). This density, combined with a bed voidage of 0.6 results in a total particulate filled crack/pore volume of $1.4 \mathrm{~L}$ in an MCO.

The bounding particulate in a scrap basket $(7.4 \mathrm{~kg})$ has not been included in this total particulate mass that defines the total crack/pore volume in an MCO because a majority of the bounding particulate estimate on fue] and scrap must be located on metal surfaces and not be constrained in a crack configuration. In addition, as shown in Figure 9.2-8, the proposed operating conditions remove all water form pores/cracks shorter than 3 to $4 \mathrm{~cm}$ in length. Since scrap pieces are generally $7.6 \mathrm{~cm}$ long, or shorter, most cracks or pores in scrap will not contain water after the hold time period. Based a hypothetical crack that is $5 \mathrm{~cm}$ long, $1 \mathrm{~cm}$ wide, and $0.01 \mathrm{~cm}$ (100 micron) thick, there would need to be 28,000 cracks in fuel within an MCO to create the crack/pore volume used in this calculation. This is equivalent to 26 of these hypothetical cracks on both ends of every inner and outer fuel element loaded in a MK IV MCO containing 270 fuel assemb1 ies. Alternatively, 4 vol\% of each inner element and 1.7 vol\% of each outer element end would be required to be composed of particulate in cracks for $5 \mathrm{~cm}$. Therefore, the bounding scrap basket particulate inventory was not included in the definition of the total crack volume.

Figure 9.2-5 indicates the impact of the total volume of material constrained in cracks on the residual water inventory estimate by repeating the calculation shown on Figure 9.2-3 using the best estimate fuel particulate in fuel and scrap of $2.38 \mathrm{~kg}$ from Sloughter, et.a1. (1997). 
Figure 9.2-3. Residual water estimate in fuel pores (constant bed voidage of 0.6 )

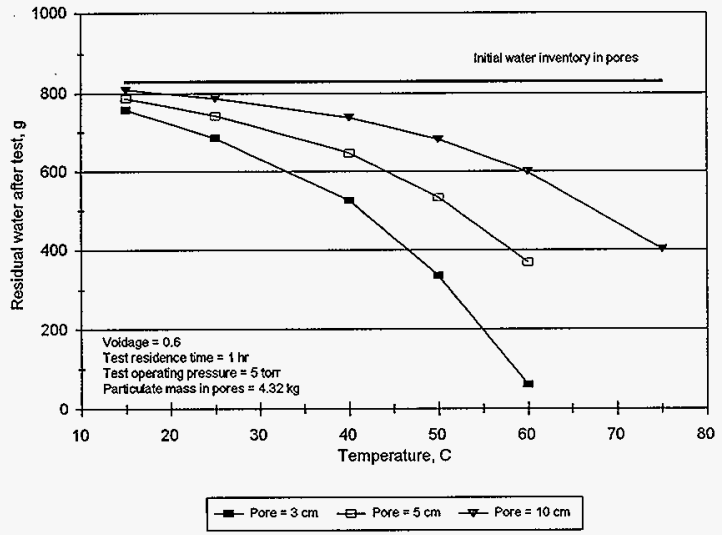

a) Test residence time $=1 \mathrm{hr}$

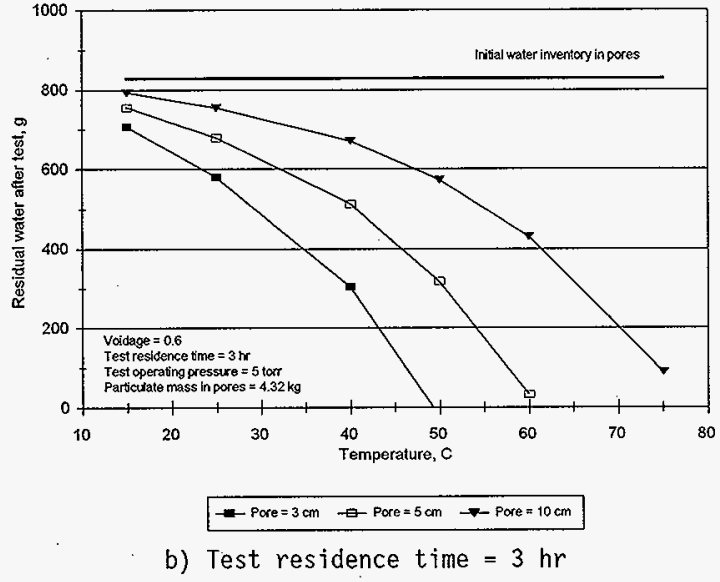


HNF-1851, Rev 0

Figure 9.2-4. Spreadsheet calculating residual water in an MCO based on Equation 9.2-12.

\begin{tabular}{|c|c|c|c|c|c|c|c|}
\hline \multicolumn{8}{|c|}{ Residual water estimate based on constant bed voidage } \\
\hline & & & & & & & \\
\hline$M p=$ & 4.32 & $\mathrm{~kg}=$ & 9.504 & $\mathrm{lb}$ & & & \\
\hline rhop $=$ & 7.8 & $g / c c=$ & 486.72 & $\mathrm{lb} / \mathrm{cuft}$ & & & \\
\hline & & & & & & & \\
\hline epsilon $=$ & 0.6 & & & & & & \\
\hline$g c=$ & 32.17 & \multicolumn{2}{|l|}{$\mathrm{lb}-\mathrm{ft} / \mathrm{bf}-\sec ^{\wedge} 2$} & $\mathrm{Dp}=$ & 4.921E-05 & $\mathrm{ft}$ & \\
\hline$M=$ & 18 & lb/bmol & & $z=$ & 1 & & \\
\hline phi $=$ & 0.6 & & & $R=$ & 1546 & \multicolumn{2}{|l|}{ ft-lbffnbmol-R } \\
\hline \multicolumn{2}{|c|}{ Operating pressure $=$} & \multirow[t]{2}{*}{5} & torr $=$ & 13.93 & $\mid \mathrm{bff} / \mathrm{ft}^{\wedge} 2$ & & \\
\hline & & & & & & & \\
\hline \multicolumn{8}{|c|}{ Saturated Steam Pressure (from Perry's 5th) and viscosity (From Hilsenrath, et al., 1955, Table 9.6) } \\
\hline \multirow[t]{3}{*}{ Temp } & $\mathrm{C}$ & 15 & 25 & 40 & 50 & 60 & 75 \\
\hline & $\mathrm{K}$ & 288 & 298 & 313 & 323 & 333 & 348 \\
\hline & $R$ & 519 & 537 & 564 & 582 & 600 & 627 \\
\hline Pressure & $\mathrm{P1}, \mathrm{lbf} / \mathrm{sq} \mathrm{ft}$ & 35.66 & 70.76 & 154.91 & 259.02 & 416.04 & 808.88 \\
\hline Viscosity & $\mathrm{lb} / \mathrm{ft}-\mathrm{sec}$ & $6.302 \mathrm{E}-06$ & $6.544 E-06$ & $6.907 E-06$ & $7.148 E-06$ & 7.39E-06 & 7.756E-06 \\
\hline \multicolumn{2}{|c|}{ Residence time $=$} & 1 & $\mathrm{hr}$, or & 3600 & sec & & \\
\hline & & & & & & & \\
\hline & & & & & & & \\
\hline \multicolumn{8}{|c|}{ Length of pore or crack dried based on parameters above and Equation $9.2-10, \mathrm{~L}$ in $\mathrm{ft}$} \\
\hline & $L=$ & 0.0084 & 0.0170 & 0.0360 & 0.0584 & 0.0909 & 0.1688 \\
\hline \multicolumn{2}{|c|}{ Max pore length } & \multicolumn{6}{|c|}{ Residual water based on temperatures and parameters above, Mw in $\mathrm{g}$} \\
\hline $\mathrm{cm}$ & $\mathrm{ft}$ & \multicolumn{6}{|c|}{ - Based on Equation 9.2-12 - } \\
\hline 1 & 0.033 & 618 & 399 & & & & \\
\hline 3 & 0.098 & 759 & 686 & 526 & 338 & 63 & \\
\hline 5 & 0.164 & 787 & 744 & 648 & 534 & 370 & \\
\hline 10 & 0.328 & 809 & 787 & 739 & 682 & 600 & 403 \\
\hline Initial wate & & 830 & 830 & 830 & 830 & 830 & 830 \\
\hline
\end{tabular}




$$
\text { HNF-1851, Rev } 0
$$

Figure 9.2-5. Residual water estimate in fuel pores based on best estimate particulate inventory (constant bed voidage $=0.6$ )

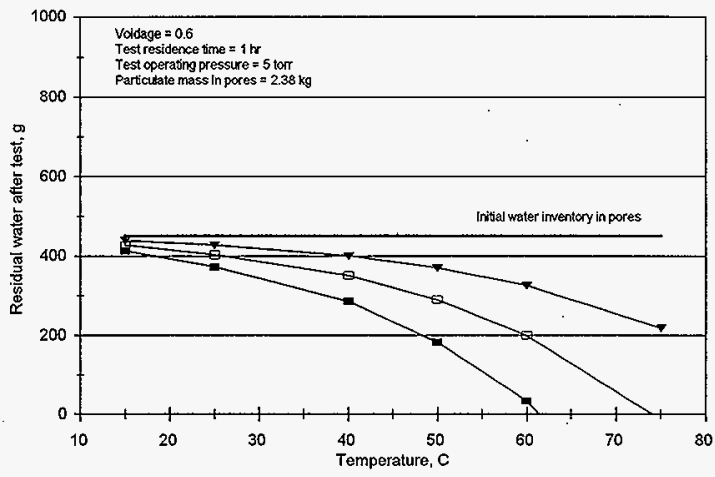

- - - Pore $=3 \mathrm{~cm} \quad \Xi-$ Pore $=5 \mathrm{~cm} \quad-7-$ Pore $=10 \mathrm{~cm}$

a) Test residence time $=1 \mathrm{hr}$

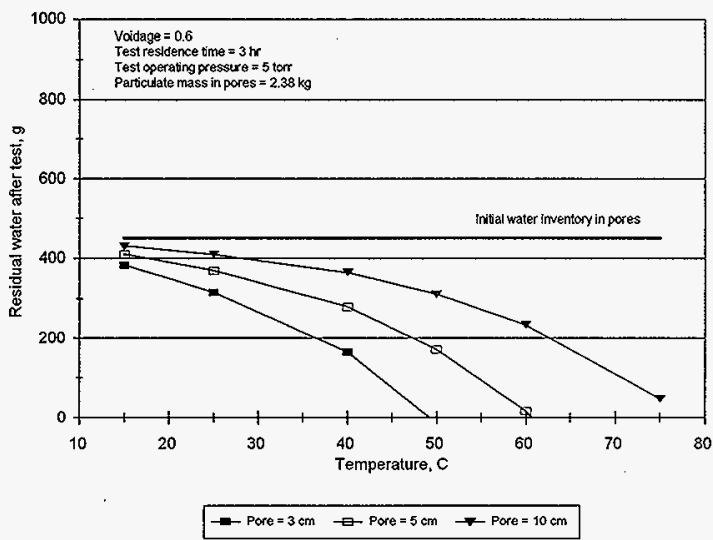

b) Test residence time $=3 \mathrm{hr}$ 
If the bed voidage is allowed to vary such that the residual water estimate is always maximized at the conditions under consideration, the Equation 9.2-15 can be used to modify Equations 9.2-10, 9.2-12, and 9.2-13 as follows.

$$
\begin{aligned}
\frac{\epsilon}{(1-\epsilon)} & =\frac{1}{2 a} \\
L & =\frac{L_{\text {tot }}}{2} \\
M_{w} & =\frac{\left(\frac{1}{4}\right)\left(\frac{\rho}{\rho_{\rho}}\right)\left(\frac{M_{\rho}}{\phi_{s}}\right)\left(\frac{L_{\alpha}}{D_{\rho}}\right)}{\sqrt{\frac{\left(\rho_{1}^{2}-p_{2}^{2}\right) g_{c} M T}{200 \rho R T \mu}}} \\
W_{t} & =\frac{M_{\mathrm{w}}}{\mathrm{T}}
\end{aligned}
$$

Figure 9.2-6 provides an indication of the residual water estimate based on this conservative assumption for bed voidage. Figure 9.2-7 provides the spreadsheet calculation used to develop the plots in Figure 9.2-6.

Note that Figure 9.2-6 provides unreal istically conservative results. This is apparent from Equation 9.2-16 which indicates the length of pore dried is independent of the test duration. This implies that the analysis is effectively varying the bed voidage with time such that only $\frac{1}{2}$ the pore or crack length can be dried. Therefore, the constant bed voidage calculations shown on Figures 9.2-3 and 9.2-5 are used to evaluate the porous bed flow model.

\subsubsection{Pressure Rise Test based on Porous Bed Flow Model}

It does not appear feasibie to design a pressure rise test that indicates the residual water inventory in an MCO based on this flow model. This conclusion is based on the model predicting that the mass rate of gas will decrease with time, independent of the residual water mass. The proposed alternative to a pressure test is based on holding the $M C 0$ at a temperature for a specified time period such that the modeling equations indicate residual water is decreased to less than $200 \mathrm{~g}$, assuming all residual water is constrained in a pore model configuration. 


\section{HNF-1851, Rev 0}

Figure 9.2-6. Residual water estimate based on porous bed model varying bed voidage for maximum residual water.

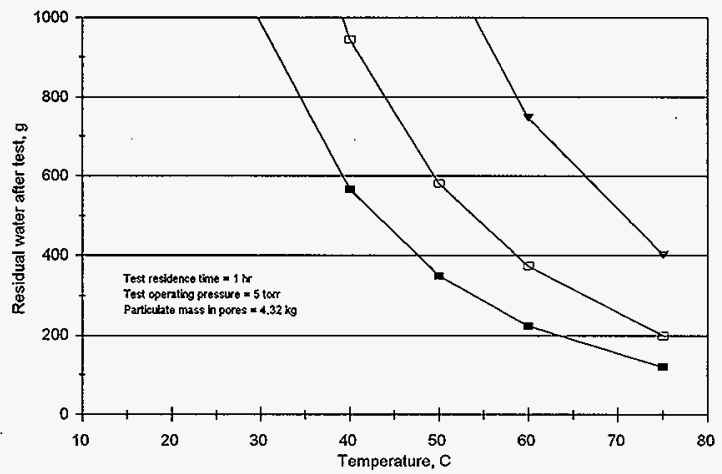

$$
\rightarrow \text { Pore }=3 \mathrm{~cm} \rightarrow \text { Pore }=5 \mathrm{~cm} \rightarrow \text { POre }=10 \mathrm{~cm}
$$

a) Test residence time $=1 \mathrm{hr}$

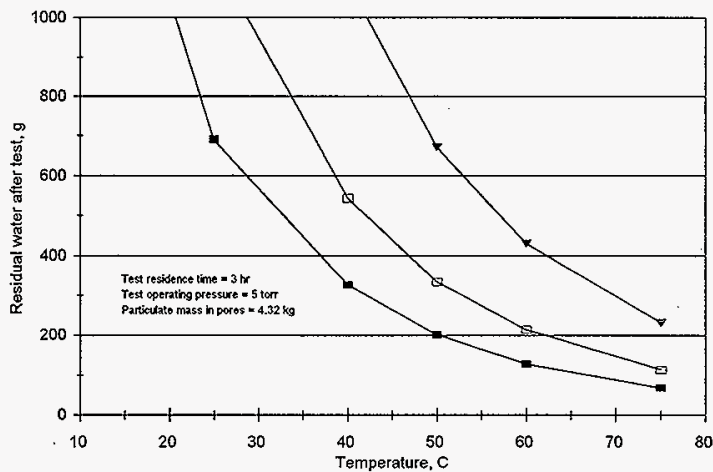

$$
- \text { - Pore }=3 \mathrm{~cm} \quad \square \text { Pore }=5 \mathrm{~cm}-\text { Pore }=10 \mathrm{~cm}
$$

b) Test residence time $=3 \mathrm{hr}$ 


$$
\text { HNF-1851, Rev } 0
$$

Figure 9.2-7. Spreadsheet calculating residual water in an MCO based on Equation 9.2-16.

\begin{tabular}{|c|c|c|c|c|c|c|c|}
\hline \multicolumn{8}{|c|}{ Residual water estimate variation assuming voidage for maximum water } \\
\hline $\mathrm{Mp}=$ & 4.32 & $\mathrm{~kg}=$ & 9.504 & $\mathrm{lb}$ & & & \\
\hline rhop $=$ & 7.8 & $\mathrm{~g} / \mathrm{cc}=$ & 486.72 & $\mathrm{lb} / \mathrm{cu} \mathrm{ft}$ & & & \\
\hline & & & & & & & \\
\hline $\mathrm{gc}=$ & 32.17 & \multicolumn{2}{|l|}{$\mathrm{lb}-\mathrm{ft} / \mathrm{bf}-\mathrm{sec}^{\wedge} 2$} & $D p=$ & $4.921 E-05$ & $\mathrm{ft}$ & \\
\hline$M=$ & 18 & $\mathrm{lb} / \mathrm{bmol}$ & & $Z=$ & 1 & & \\
\hline phi $=$ & 0.6 & & & $R=$ & 1546 & \multicolumn{2}{|c|}{$\mathrm{ft}-\mathrm{b}$ f/lbmol-R } \\
\hline \multicolumn{2}{|c|}{ Operating pressure $=$} & 5 & torr $=$ & 13.93 & $\mathrm{Ibf} / \mathrm{ft}^{\wedge} 2$ & & \\
\hline \multicolumn{8}{|c|}{ Saturated Steam Pressure (from Perry's 5th) and viscosity (From US Dept of Commerce, Circ 564, Table 9.6) } \\
\hline \multirow[t]{3}{*}{ Temp } & $\mathrm{C}$ & 15 & 25 & 40 & 50 & 60 & 75 \\
\hline & $\mathrm{K}$ & 288 & 298 & 313 & 323 & 333 & 348 \\
\hline & $\mathrm{R}$ & 519 & 537 & 564 & 582 & 600 & 627 \\
\hline \multicolumn{2}{|c|}{ Pressure, $\mathrm{P} 1, \mathrm{lbf} / \mathrm{sg} \mathrm{ft}$} & 35.66 & 70.76 & 154.91 & 259.02 & 416.04 & 808.88 \\
\hline Viscosity & $\mathrm{lb} / \mathrm{t} \mathrm{t}-\mathrm{sec}$ & $6.302 \mathrm{E}-06$ & $6.544 \mathrm{E}-06$ & $6.907 \mathrm{E}-06$ & $7.148 \mathrm{E}-06$ & $7.39 \mathrm{E}-06$ & $7.756 E-06$ \\
\hline \multicolumn{2}{|l|}{ Residence time $=$} & 1 & $\mathrm{hr}$, or & 3600 & sec & & \\
\hline & & & & & & & \\
\hline \multicolumn{2}{|l|}{ Max pore length } & & & & & & \\
\hline $\mathrm{cm}$ & $\mathrm{ft}$ & \multicolumn{6}{|c|}{ Residual water based on temperatures and parameters above, $M w$ in $\mathrm{g}$} \\
\hline 1 & 0.033 & 814 & 399 & 189 & 117 & 75 & 40 \\
\hline 3 & 0.098 & 2443 & 1198 & 567 & 350 & 225 & 121 \\
\hline 5 & 0.164 & 4071 & 1997 & 946 & 583 & 374 & 202 \\
\hline 10 & 0.328 & 8143 & 3994 & 1891 & 1166 & 749 & 403 \\
\hline
\end{tabular}




\section{HNF-1851, Rev 0}

Figure 9.2-8 indicates the variation of residual water in pores with residence time at $40^{\circ} \mathrm{C}$ and an operating pressure of 5 torr. Residence times greater than $12 \mathrm{hr}$ reduce the water inventory in pores to less than $200 \mathrm{~g}$ if all pores are modeled as $5 \mathrm{~cm}$ long. However, much longer times are required if pores are modeled as $10 \mathrm{~cm}$ long. The residence time is reduced to $4 \mathrm{hr}$ if cracks are $3 \mathrm{~cm}$ long. In reality, a wide variety of crack lengths will be encountered in actual fuel. To investigate the impact of crack length variation, a simple distribution was assumed where $25 \%$ of the crack volume is as $3 \mathrm{~cm}$ long cracks, $50 \%$ as $5 \mathrm{~cm}$ cracks, and $25 \%$ as $10 \mathrm{~cm}$ cracks. This result is also shown on Figure 9.2-8. Based on these results, a residence time of $20 \mathrm{hr}$ was selected to conservatively conclude that the free water will be reduced to less than $200 \mathrm{~g}$.

Figure 9.2-8. Variation of residual water in pores/cracks with residence time at $40^{\circ} \mathrm{C}$

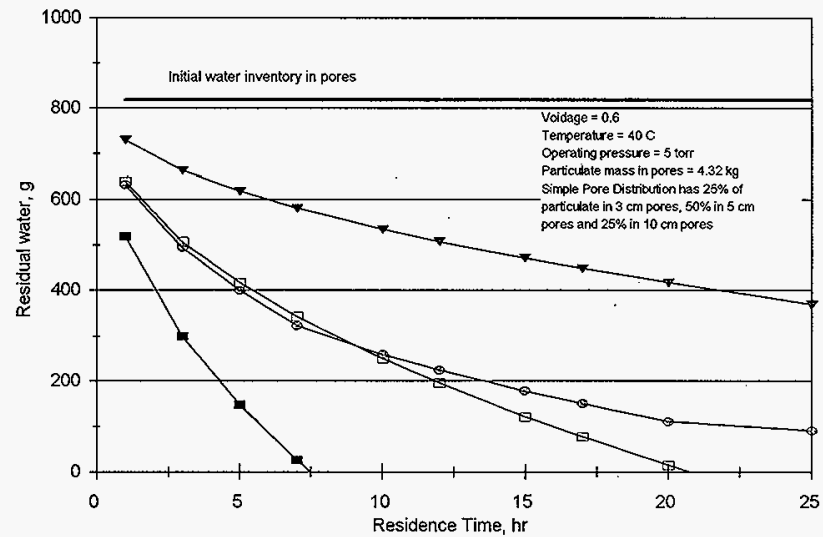

$\rightarrow-$ Pore $=3 \mathrm{~cm} \quad \rightarrow$ Pore $=5 \mathrm{~cm} \quad \rightarrow$ Pore $=10 \mathrm{~cm}$ Simple Pore Distribution




$$
\text { HNF-1851, Rev } 0
$$

The calculations developed above are based on an operating pressure of 5 torr. Figure 9.2-9 indicates the sensitivity of residual water estimates to the operating pressure. Based on this comparison, the calculations are considered applicable if the operating pressure is less than 20 torr during the drying of cracks and pores at $40^{\circ} \mathrm{C}$.

Figure 9.2-9. Variation of residual water in pores/cracks with operating pressure during drying for $20 \mathrm{hr}$ at $40^{\circ} \mathrm{C}$

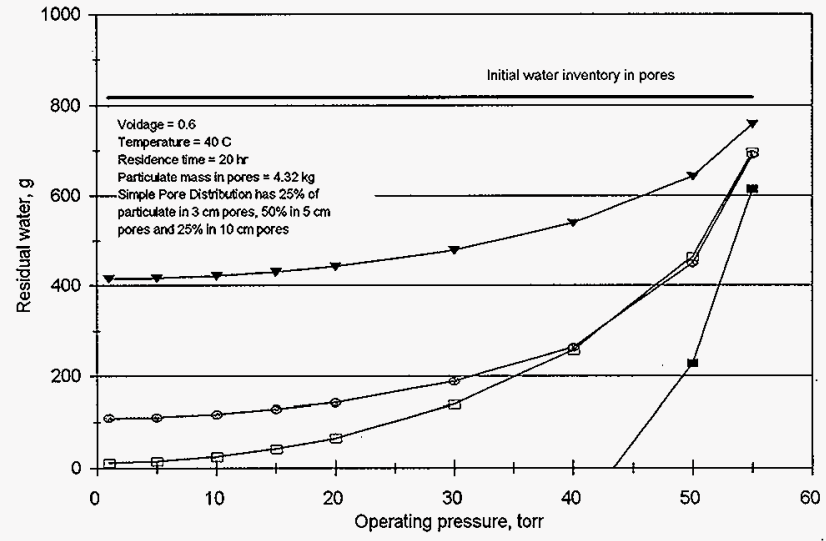




\subsection{Drying Performance using a Pore Diffusion Model}

This section develops modeling equations for drying of pores or cracks in fuel pieces based on a diffusion model. This type of model is applicable when the MCO gas pressure is greater than the saturation pressure of water at the fuel temperature. This condition would typically occur when the MCO is backfilled with helium to pressures in excess of atmospheric pressure.

The modeling equation development does not result in finding a pressure rise measurement that can show residual free water is less than a particular criterion. However, the diffusion analysis can be used to define an operating procedure (hoid MCO fuel at a selected temperature for a time period) that can form the basis for concluding free water has been reduced below a criterion. The diffusion equations predict the rate that a liquid interface recedes into a fuel crack or pore (Equation 9.3-4) based on operating conditions. Based on this relationship, and a total pore or crack length, the residual free water in pores as a function of residence time can be estimated (Equation 9.3-9).

Parametric variations were used to find condition that can form a basis for concluding free water is less than $200 \mathrm{~g}$. It was found that operating temperatures above $50^{\circ} \mathrm{C}$ are required for the diffusion model to predict a reasonable operating time. Therefore, Section 9.5 was developed to provide a basis for allowing operation at temperatures up to $75^{\circ} \mathrm{C}$. The operating time period definition is based on a fuel temperature of $65^{\circ} \mathrm{C}$ as a conservative approach of fuel temperature to the MCO wall temperature when the tempered water heating an $\mathrm{MCO}$ is set at, or slightly below, $75^{\circ} \mathrm{C}$.

\subsection{Diffusion from Pores and Cracks}

This appendix develops the equation used to estimate the variation in time to remove water from a crack or defect in a fuel element with operating conditions when limited by diffusion through helium. This is a model of water removal during helium recycle operations. The fuel gap is modeled as an open pore of arbitrary cross section that begins filled with water. An interface of water within the pore is assumed to produce a water concentration equivalent to saturated steam at the operating conditions. Bulk flow is assumed to be sufficient to maintain the water concentration at the element surface at essentially zero (the implication of the bulk gas water concentration assumption is investigated as a parametric variation in Section 9.3.2). As water evaporates from the pore, the water interface retreats down the pore length until all water is removed. A pseudo-steady state analysis is used to estimate the total time for complete water removal. 
The mass flux from diffusion is estimated using Equation 14-4 from Perry and Chilton (1973) (see pg 14-4) for steady state diffusion of one component through a second stagnant component. This equation is arranged for the diffusing component to transfer away from the interface as follows.

$$
\begin{aligned}
N_{A} & =\frac{D_{G} P\left(y_{i}-y\right)}{R T B_{F}(1-y)_{l m}} \\
\text { where }(1-y)_{l m} & =\frac{(1-y)-\left(1-y_{i}\right)}{\ln \left(\frac{1-y}{1-y_{i}}\right)}=\frac{y_{i}-y}{\ln \left(\frac{1-y}{1-y_{i}}\right)} \\
N_{A} & =\frac{D_{G} P}{R T B_{F}} \ln \left(\frac{1-y}{1-y_{i}}\right) .
\end{aligned}
$$

where: $N_{A}=$ mass flux of the diffusing component, gmol/sec-cm ${ }^{2}$

$D_{G}=$ diffusivity, $\mathrm{cm}^{2} / \mathrm{sec}$

$\mathrm{P}=$ absolute pressure, atm

$\mathrm{R}=$ gas constant, $82.06 \mathrm{~atm}-\mathrm{cm}^{3} / \mathrm{gmol}-\mathrm{K}$

$\mathrm{T}=$ absolute temperature, $\mathrm{K}$

$B_{F}=$ diffusion path length, $\mathrm{cm}$

$y_{i}=$ mole fraction of diffusing component at the interface

$y=$ mole fraction of diffusing component at distance $B_{F}$ from interface.

The assumption that the water concentration is negligible in the bulk flow results in $y=0$. Therefore, noting that $y_{i}=p_{i} / P$ where $p_{i}$ is the partial pressure of water vapor at the interface, Equation 9.3-1 simplifies to the following.

$$
\begin{aligned}
N_{A} & =\frac{D_{G} P}{R T B_{F}} \ln \left(\frac{1}{1-y_{i}}\right) \\
& =-\frac{D_{G} P}{R T B_{F}} \ln \left(1-y_{i}\right) \\
& =-\frac{D_{G} P}{R T B_{F}} \ln \left(1-\frac{p_{i}}{P}\right)
\end{aligned}
$$

The mass flux from the pore is a function of the diffusion path length. Therefore, as the water interface recedes into the pore, the mass flux decreases. The time to empty the pore volume of water can be estimated by a pseudo-steady state evaluation as was done in the previous section. For an arbitrary pore cross sectional area, $A$, the following equation describe the pseudo steady state analysis.

$$
\begin{aligned}
\text { Water mass in a length increment } & =\left(A, \mathrm{~cm}^{2}\right)\left(\rho, \frac{\mathrm{g}}{\mathrm{cm}^{3}}\right)(\Delta z, \mathrm{~cm}) \\
& =A \rho(\Delta z), g \\
\text { Water mass removed in a time increment } & =\left(A, \mathrm{~cm}^{2}\right)\left(N_{A}, \frac{\mathrm{gmol}}{\mathrm{cm}^{2}-\mathrm{sec}}\right)\left(M_{1}, \frac{g}{\mathrm{gmol}}\right)(\Delta t, \mathrm{sec}) \\
& =A N_{A} M_{1}(\Delta t), g
\end{aligned}
$$


where $\rho$ is the density of Tiquid water and $M_{1}$ is the molecular weight of water. This results in

$$
\begin{aligned}
\rho A(\Delta z) & =N_{A} A M_{1}(\Delta t), \text { or } \\
\frac{d z}{d t} & =\frac{N_{A} M_{1}}{\rho}, \text { as increments approach } 0
\end{aligned}
$$

Let

$$
\beta=-\frac{D_{G} P}{R T} \ln \left(1-\frac{p_{i}}{P}\right) \text {, such that } N_{A}=\frac{\beta}{B_{F}}
$$

then

$$
\frac{d z}{d t}=\frac{\beta M_{1}}{\rho z}
$$

Solving this yields

$$
\begin{aligned}
\int_{0}^{B_{F}} z d z & =\frac{\beta M_{1}}{\rho} \int_{0}^{T} d t \\
\frac{B_{F}^{2}}{2} & =\frac{\beta M_{1} T}{\rho} \\
T & =\frac{\rho B_{F}^{2}}{2 \beta M_{1}}, \text { or } \\
T & =-\frac{\rho B_{F}^{2} R T}{2 M_{1} D_{G} P \ln \left(1-\frac{p_{i}}{P}\right)}
\end{aligned}
$$

- Checking units,

$$
\mathrm{T}=\frac{\left(\frac{\mathrm{g}}{\mathrm{cm}^{3}}\right)(\mathrm{cm})^{2}\left(\frac{\mathrm{atm}-\mathrm{cm}^{3}}{\mathrm{gmol}-K}\right)(K)}{\left(\frac{\mathrm{g}}{\mathrm{gmol}}\right)\left(\frac{\mathrm{cm}^{2}}{\mathrm{sec}}\right)(\mathrm{atm})}=\mathrm{sec}
$$

\subsubsection{Diffusion Parameters and Parametric Variations}

The diffusivity of water vapor in helium is estimated based on Equation 3-29 in Perry and Chilton (1973) (see pg 3-231).

$$
D_{G}=\frac{B T^{3 / 2} \sqrt{\left(1 / M_{1}\right)+\left(1 / M_{2}\right)}}{P r_{12}^{2} I_{D}}
$$

where: $\quad D_{G}=$ diffusivity, $\mathrm{cm}^{2} / \mathrm{sec}$

$T=$ absolute temperature, $K$

$\mathrm{P}=$ absolute pressure, atm

$M_{1}=$ molecular weight of water, $18 \mathrm{~g} / \mathrm{gmol}$

$\mathrm{M}_{2}=$ molecular weight of helium, $4 \mathrm{~g} / \mathrm{gmol}$ 


$$
\begin{aligned}
& \text { HNF-1851, Rev } 0 \\
& B=\left(10.85-2.50 \sqrt{\left(1 / M_{1}\right)+\left(1 / M_{2}\right)}\right) \times 10^{-4} \\
& =9.47 \times 10^{-4} \\
& r_{12}=\text { collision diameter } \hat{\AA} \\
& =\frac{\left(r_{0}\right)_{1}+\left(r_{0}\right)_{2}}{2} \\
& =2.678 \AA \\
& \text { where }\left(r_{0}\right)_{1}=2.655 \AA \text { (water) and }\left(r_{0}\right)_{2}=2.7 \AA \text { (helium) from Table 3-308 in Perry and Chilton (1973). } \\
& I_{0}=\quad \text { collision integral which is read from Tables 3-308 and 3-309 of Perry and Chilton (1973). For the }
\end{aligned}
$$

Noting that the term $\left(D_{G} P\right)$ is the actual term of interest, Equation $9.3-6$ is rearranged and values substituted as follows.

$$
\begin{aligned}
D_{G} P & =\frac{\left(9.47 \times 10^{-4}\right) T^{3 / 2} \sqrt{(1 / 18)+(1 / 4)}}{\left(2.678^{2}\right)(0.4)} \\
& =\left(1.825 \times 10^{-4}\right) T^{3 / 2}, \frac{\mathrm{cm}^{2}-\mathrm{atm}}{\mathrm{sec}}
\end{aligned}
$$

Other parameter values -

$$
\begin{aligned}
& \rho=1 \text { iquid water density }=1 \mathrm{~g} / \mathrm{cm}^{3} \\
& R=\text { gas constant }=82.06 \mathrm{~atm}-\mathrm{cm}^{3} / \mathrm{gmol}^{3} \mathrm{~K} \\
& \mathrm{p}_{\mathrm{i}}=\text { saturated steam pressure at operating temperature } \\
& \mathrm{P}=\text { absolute operating pressure } \\
& \mathrm{T}=\text { absolute operating temperature, } \mathrm{K}
\end{aligned}
$$

Test calculation:

Choose operating conditions of $40^{\circ} \mathrm{C}$ and helium recycle pressure $(P)$ of 760 torr as a check calculation. Therefore, $\mathrm{T}=40^{\circ} \mathrm{C}=313 \mathrm{~K}$ and $\mathrm{p}_{i}=55.6$ torr from the saturated steam data. For $B_{F}=1 \mathrm{~cm}$ and substituting the Equation 9.3-7 into 9.3-5 yields the following.

$$
\begin{aligned}
T & =-\frac{\rho B_{F}^{2} R}{2\left(M_{1}\right)\left(1.825 \times 10^{-4}\right) \sqrt{T} \ln \left(1-\frac{p_{i}}{P}\right)} \\
& =-\frac{(1)\left(1^{2}\right)(82.06)}{2(18)\left(1.825 \times 10^{-4}\right) \sqrt{323} \ln \left(1-\frac{87.5}{760}\right)} \\
& =5,682 \mathrm{sec}=1.6 \mathrm{hr}
\end{aligned}
$$

Parametric variations of the pore drying time (Equation 9.3-8) with pore length, operating temperature, and operating pressure were calculated for $40^{\circ} \mathrm{C}$ and $65^{\circ} \mathrm{C}$ and pressures of 760 torr and 1000 torr. The parametric variation 
HNF-1851, Rev 0

results are indicated on Figure 9.3-1. Figure 9.3-2 indicates an excerpt of the spreadsheet calculation of drying times. Note that the entry for pore length of $1 \mathrm{~cm}, 50^{\circ} \mathrm{C}$, and 760 torr is equivalent to the test calculation for Equation 9.3-8.

The parametric analysis indicates that drying times predicted by the diffusion model are reduced by increased operating temperature and/or decreased operating pressure. Alternately, the length of pore dried in a given time period is increased by increased operating temperature or decrease operating pressure.

Figure 9.3-1. Variation of drying time with pore length, temperature and pressure based on water diffusion through helium.

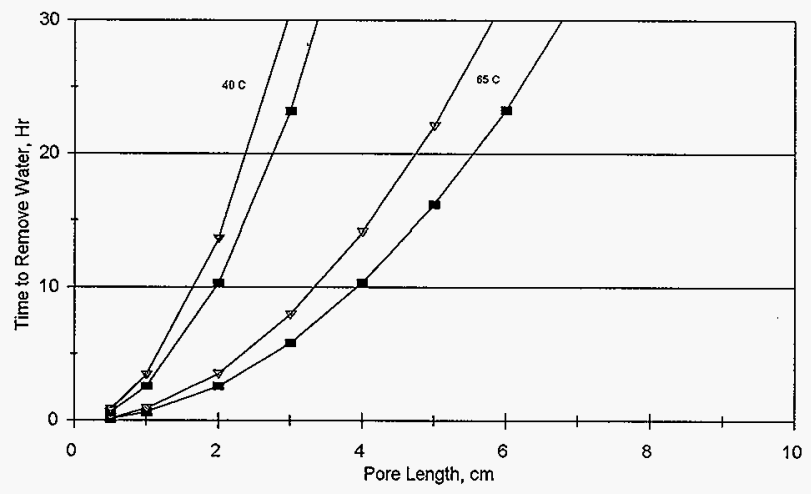

700 torr Op Pressure $\quad 1000$ torr Op Pressure 
HNF-1851, Rev 0

Figure 9.3-2. Spreadsheet calculating drying times using Equation 9.3-8.

\begin{tabular}{|c|c|c|c|c|c|c|c|c|c|}
\hline \multirow{2}{*}{\multicolumn{2}{|c|}{\begin{tabular}{l|l} 
& $N B f=-$ \\
Steam Table data:
\end{tabular}}} & $2.22 \mathrm{E}-06$ & \multicolumn{7}{|c|}{$(T)^{\wedge} 0.5 \operatorname{Ln}(1-\mathrm{p} / \mathrm{P}) \mathrm{gmal} / \mathrm{sec}-\mathrm{cm}$} \\
\hline & & & & & & & & & \\
\hline \multicolumn{2}{|c|}{ Op temps } & \multicolumn{2}{|c|}{ Sat Steam Press, pi } & & \multicolumn{5}{|c|}{$\mathrm{N} \mathrm{Bf}$ for various operating pressures, $\mathrm{P}$} \\
\hline c & K & psia & torr & Press,torr & 300 & 500 & 760 & 1000 & 1250 \\
\hline 40 & 313 & 1.0758 & 55.63 & & $8.07 E-06$ & 4.64E-06 & $2.99 \mathrm{E}-06$ & $2.25 E-06$ & $1.79 \mathrm{E}-06$ \\
\hline \multirow[t]{2}{*}{75} & 348 & 5.5923 & 289.20 & & $1.38 E-04$ & $3.58 \mathrm{E}-05$ & $1.99 \mathrm{E}-05$ & 1.42E-05 & $1.09 \mathrm{E}-05$ \\
\hline & \multicolumn{9}{|c|}{ Time to remove water equivalent to the void pore volume } \\
\hline & \multicolumn{3}{|c|}{ Time $=($ (rho $) B^{\wedge} 2 /(2)(18)(\mathrm{N} B f), \sec$} & & \multicolumn{2}{|c|}{$\mathrm{N}$ in gmolssec-cm } & & & \\
\hline & & & & & & & & & \\
\hline & & & & & \multicolumn{3}{|c|}{ mo $=$ density of water, $\mathrm{g} / \mathrm{cu} \mathrm{cm}(1 \mathrm{~g} / \mathrm{cc})$} & & \\
\hline & rho $=$ & 1 & $\mathrm{~g} / \mathrm{cc}$ & & $\mathrm{Bf}$ in $\mathrm{cm}$ & & & & \\
\hline & & & & & & & & & \\
\hline & & & & & & & & & \\
\hline \multirow[t]{2}{*}{ Temp $=$} & 40 & c & & & & & & & \\
\hline & & \multicolumn{5}{|c|}{ Time to remove water equivalent to pore volume, $\mathrm{Hr}$} & & & \\
\hline $\mathrm{Bf}, \mathrm{cm}$ & Press, torr & 300 & 500 & 760 & 1000 & 1250 & & & \\
\hline 0.5 & & 0.24 & 0.42 & 0.64 & 0.86 & 1.08 & & & \\
\hline 1 & & 0.96 & 1.66 & 2.58 & 3.43 & 4.31 & & & \\
\hline 2 & & 3.82 & 6.65 & 10.32 & 13.70 & 17.23 & & & \\
\hline 3 & & 8.60 & 14.96 & 23.22 & 30.83 & 38.76 & & & \\
\hline 4 & & 15.30 & 26.60 & 41.27 & 54.81 & 68.91 & & & \\
\hline 5 & & 23.90 & 41.56 & 64.49 & 85.64 & 107.68 & & & \\
\hline 6 & & 34.42 & 59.85 & 92.86 & 123.33 & 155.05 & & & \\
\hline 7.5 & & 53.78 & 93.51 & 145.10 & 192.70 & 242.27 & & & \\
\hline 10 & & 95.60 & 166.24 & 257.95 & 342.57 & 430.71 & & & \\
\hline
\end{tabular}

An estimate of residual water based on the pore diffusion model can be developed from a mass balance similar to that presented by Equations 9.2-11 and 9.2-12. This results in the following estimate for residual water.

$$
M_{W}=\left(\frac{\epsilon}{1-\epsilon}\right)\left(\frac{\rho}{\rho_{p}}\right) M_{p}\left(1-\frac{B_{F}}{B_{F, t \alpha}}\right)
$$

Figure 9.3-2 indicates the variation of residual water in an MCO with residence time based on Equations 9.3-9 and 9.3-4. For this calculation, the volume of fuel pores was assumed to be defined by the bounding quantity of particulate in fuel and voidage as defined for the porous bed model in Section 9.2 . 
HNF-1851, Rev 0

Figure 9.3-2. Residual water content in fuel pores based on diffusion model of drying.

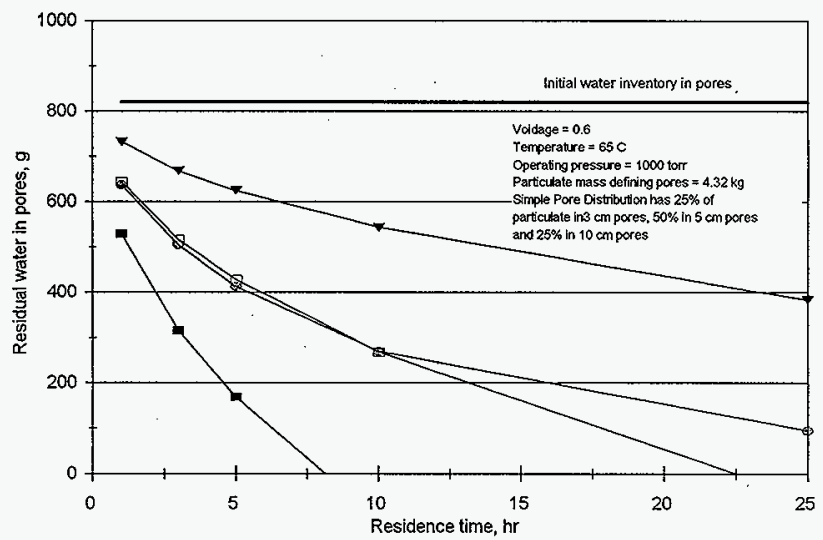

$\rightarrow-$ Pore $=3 \mathrm{~cm} \quad \square$ Pore $=5 \mathrm{~cm}$ - Pore $=10 \mathrm{~cm} \quad-$ Simple Pore Distribution

The analysis leading to Figure 9.3-2 assumes the concentration of water vapor in bulk gas outside the fuel element is zero. This is not physically possible in the MCO system. Therefore, the effect of varying the bulk gas water concentration was investigated. Eliminating the simplifying assumption used to derive Equation $9.3-2$ results in modifying the constant, $\beta$, in Equation 9.3-4 to the following.

$$
\beta=-\frac{D_{G} P}{R T} \ln \left(\frac{1-p / P}{1-p_{b} / P}\right) .
$$

where: $p_{b}=$ partial pressure of water vapor in the bulk gas.

Equation 9.3-4 remains applicable such that

$$
T=\frac{\rho B_{F}^{2}}{2 \beta M_{1}}
$$

Equations 9.3-9, 9.3-10 and 9.3-11 are used to develop Figure 9.3-3, which shows the variation of residual water with bulk gas water concentration after holding an $\mathrm{MCO}$ at $65^{\circ} \mathrm{C}$ for $20 \mathrm{hr}$. Figure 9.3-3 indicates the residual water 
estimate, based on the diffusion analysis, in relatively insensitive to bulk gas water partial pressures that range from 0 to 30 torr.

Figure 9.3-3. Variation of residual water content with bulk gas water concentration.

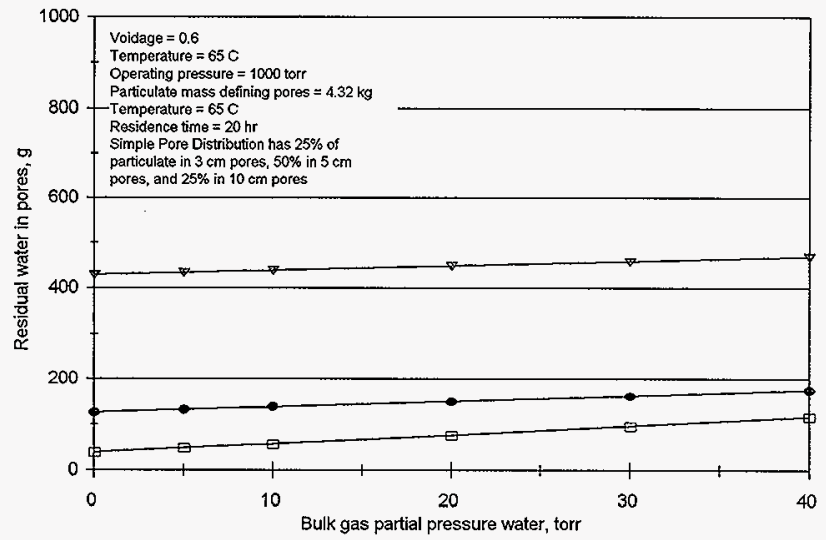

\subsubsection{Pressure Rise Test based on Pore Diffusion Model}

As with the pore/crack model described in Section 9.2, it does not appear feasible to design a pressure rise test that indicates the residual water inventory in an MCO based on this flow model. This conclusion is based on the model predicting that the mass rate of gas will decrease with time, independent of the residual water mass. The proposed alternative to a pressure test is based on holding the $\mathrm{MCO}$ at $65^{\circ} \mathrm{C}$ for $20 \mathrm{hr}$ such Figure $9.3-2$ indicates residual water is decreased to less than $200 \mathrm{~g}$, assuming all residual water is constrained in a pore model configuration. 


\section{HNF-1851, Rev 0}

\subsection{Pressure Rise Test Uncertainty Estimate}

The pressure rise test is a measure of effects that cause a phase change of the materials within an MCO during the test period at the conditions created during the test. The phase changes monitored can result from either a physical phase change, such as,

$$
\begin{aligned}
& \mathrm{H}_{2} \mathrm{O}(\mathrm{s}) \rightarrow \mathrm{H}_{2} \mathrm{O}(\mathrm{g}) \\
& \mathrm{H}_{2} \mathrm{O}(\mathrm{l}) \rightarrow \mathrm{H}_{2} \mathrm{O}(\mathrm{g})
\end{aligned}
$$

or from chemical reactions, such as,

$$
\begin{aligned}
H_{2} \mathrm{O}(I)+\alpha, \beta, \gamma & \rightarrow \mathrm{H}_{2}(g)+\frac{1}{2} \mathrm{O}_{2} \\
U+2 \mathrm{H}_{2} \mathrm{O}(I) & -U \mathrm{O}_{2}+2 \mathrm{H}_{2}(g)
\end{aligned}
$$

The pressure rise test does not necessarily determine if a gas or gas/solid phase reaction is occurring within the MCO. An example of this situation is as follows.

$$
\mathrm{U}+2 \mathrm{H}_{2} \mathrm{O}(g) \rightarrow U \mathrm{O}_{2}+2 \mathrm{H}_{2}(g)
$$

The pressure rise test measures a mass rate of gas entering the void space of the MCO. The mass rate is calculated from the test conditions and measurements based on the ideal gas law. Figure 9.4-1 indicates the system during the test. The gas rate is calculated from the test based on the following equation.

$$
\dot{n}=\frac{P^{\prime} V}{R T}=\frac{\left(p_{2}-p_{1}\right) V}{T R T}, g m o l / h r
$$

where: $p_{1}, p_{2}=$ initial and final test pressures, torr

$T=$ test duration, $h r$

$V=$ MCO void volume, $L$

$T=$ absolute temperature, $\mathrm{K}$

$\mathrm{R}=$ gas constant, $0.082 \mathrm{~atm}-\mathrm{L} / \mathrm{gmol}-\mathrm{K}=62.4$ torr $\mathrm{L} / \mathrm{gmol}-\mathrm{K}$

Equation 9.4-1 is converted to a mass rate of a particular gas by the molecular weight. Therefore, the mass rate is as follows.

$$
m=M \dot{n}=\frac{M\left(p_{2}-p_{1}\right) V}{\mathrm{~T} R T}, g / h r
$$

where: $\quad M=$ molecular weight, $\mathrm{g} / \mathrm{gmol}$ 
HNF-1851, Rev 0

Figure 9.4-1. Pressure rise test parameters

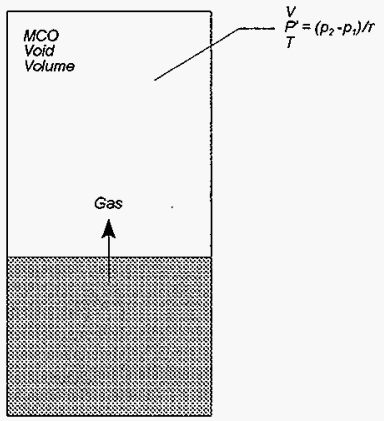

$V=M C O$ void volume, $L$

= Pressure nise rate, torm

p1 = Pressure at start of test, tor

$\rho 2=$ Pressure at end of test, torr

$r=$ Test duration, $h r$

$T=$ Gas temperature, $K$

For a particular pressure rise test, $M, V$, and $R$ in Equation 9.4-2 are constants. Therefore, the uncertainty in the measured gas mass rate is estimated by the following.

$$
\Delta m=\sqrt{\left(\frac{\partial m}{\partial p_{1}}\right)^{2}\left(\Delta p_{1}\right)^{2}+\left(\frac{\partial m}{\partial p_{2}}\right)^{2}\left(\Delta p_{2}\right)^{2}+\left(\frac{\partial m}{\partial T}\right)^{2}(\Delta T)^{2}+\left(\frac{\partial m}{\partial T}\right)^{2}(\Delta T)^{2}}
$$

The individual components of Equation 9.4-3 are as follows.

$$
\begin{aligned}
& \frac{\partial m}{\partial p_{1}}=-\frac{M V}{T R T}, \frac{\partial m}{\partial p_{2}}=\frac{M V}{T R T}, \\
& \frac{\partial m}{\partial T}=-\frac{M\left(p_{2}-p_{1}\right) V}{T^{2} R T}, \frac{\partial m}{\partial T}=-\frac{M\left(p_{2}-p_{1}\right) V}{T R T^{2}}
\end{aligned}
$$

Substituting the components into Equation 9.4-3 and simplifying resuits in the following.

$$
\Delta m=\frac{M V}{T R T} \sqrt{\left(\Delta p_{1}\right)^{2}+\left(\Delta p_{2}\right)^{2}+\left(p_{2}-p_{1}\right)^{2}\left(\frac{\Delta r}{T}\right)^{2}+\left(p_{2}-p_{1}\right)^{2}\left(\frac{\Delta T}{r}\right)^{2}}
$$

This can be further simplified by combining Equations 9.4-2 and 9.4-4 to yield the following. 


$$
\frac{\Delta m}{m}=\sqrt{\left(\frac{\Delta p_{1}}{p_{2}-p_{1}}\right)^{2}+\left(\frac{\Delta p_{2}}{p_{2}-p_{1}}\right)^{2}+\left(\frac{\Delta \mathrm{T}}{T}\right)^{2}+\left(\frac{\Delta T}{T}\right)^{2}}
$$

The uncertainty included in Equation 9.4-5 depends on the uncertainty of the instrumentation used for the pressure rise measurements. The current instrumentation for pressure measurement is expected to have an uncertainty of approximately $1 \%$ of the measured value. This is equivalent to

$$
\Delta p_{1}=p_{1}(\Delta p) \text { and } \Delta p_{2}=p_{2}(\Delta p) \text {, where } \Delta p=0.01
$$

The uncertainty in the test duration and temperature are expected to be fixed uncertainties, such that longer durations or higher temperatures reduce the contribution of these values to the mass rate uncertainty. Incorporating the pressure measurement uncertainty into Equation 9.4-5 results in the following simplified estimate of the mass rate uncertainty.

$$
\frac{\Delta m}{m}=\sqrt{\frac{\left(p_{1}^{2}+p_{2}^{2}\right)}{\left(p_{2}-p_{1}\right)^{2}}(\Delta p)^{2}+\left(\frac{\Delta T}{T}\right)^{2}+\left(\frac{\Delta T}{T}\right)^{2}}
$$

Equation 9.4-6 provides an estimate of one standard deviation of the mass rate uncertainty. Figure 9.4-2 provides a plot relating the observed pressure rise to a molar gas flow rate. Figure 9.4-3 provides a plot relating an observed pressure rise test performed at $50^{\circ} \mathrm{C}$ to a gas mass rate entering the MCO.void space assuming the gas is water vapor. The uncertainty band indicated is based on two standard deviations, assuming $\Delta p=0.01, \Delta \tau=1 \mathrm{~min}$, and $\Delta T=5 \mathrm{~K}$. Figures 9.4-2 and 9.4-3 also indicate that the assumed MCO void volume impacts the gas mass rate indicated by a pressure rise test. An MCO containing the maximum fuel loading ( 5 MK IV fuel baskets containing a total of $270 \mathrm{E}$ length assemblies) results in a void volume estimate of $500 \mathrm{~L}$. An empty MCO, containing no baskets or fuel, results in a void volume estimate of $1,000 \mathrm{~L}$. Using a mass rate 1 imit based on a $1,000 \mathrm{~L}$ MCO void volume allows the test basis to be independent of the mass loading of fuel in a particular MCO.

Figure 9.4-3 provides the basis for converting a specified gas mass rate criterion into a pressure rise rate limit at a particular operating temperature. For example, if the mass rate criterion is specified at $2 \times 10^{-6} \mathrm{~Tb} / \mathrm{sec}$, a pressure rise criterion of $3.47 \mathrm{torr} / \mathrm{hr}$ would be required to provide confidence that the measured mass rate at $50^{\circ} \mathrm{C}$ does not exceed the criterion. 
HNF-1851, Rev 0

Figure 9.4-2. Molar gas flow rate uncertainty indicated by pressure rise test at $40^{\circ} \mathrm{C}$

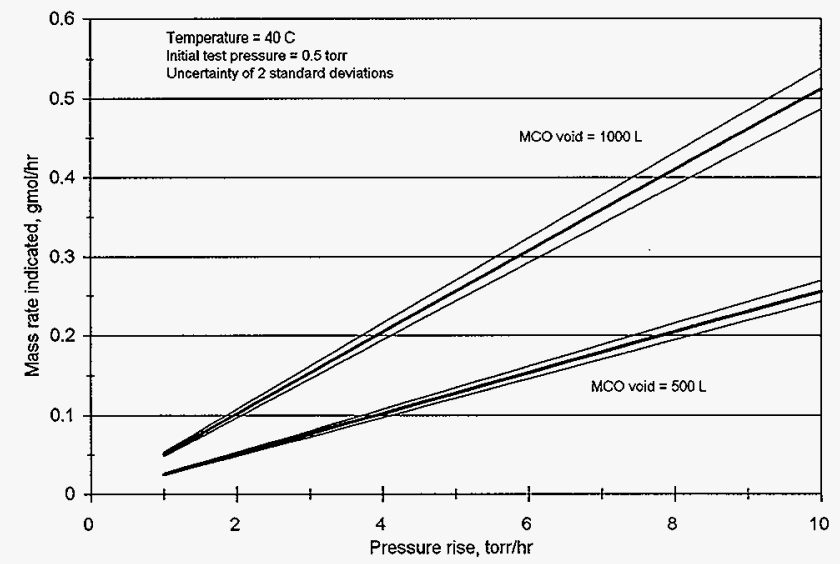


HNF-1851, Rev 0

Figure 9.4-3. Mass rate uncertainty indicated by pressure rise test at $40^{\circ} \mathrm{C}$ assuming water vapor entering the $M C 0$ void space

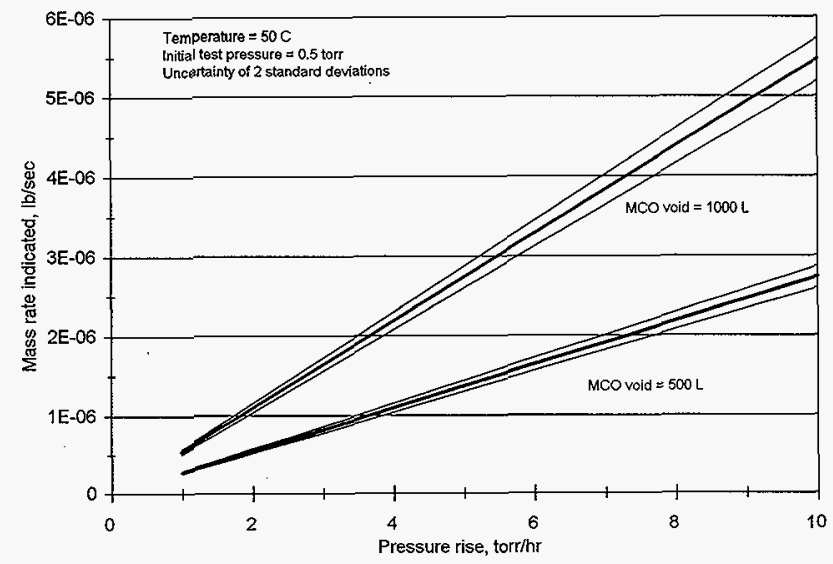




$$
\text { HNF-1851, Rev } 0
$$

9.5 Cold Vacuum Drying Operating Stability at $75^{\circ} \mathrm{C}$

A pressure rise test at one temperature is useful in verifying that water removal is sufficient to allow process operation at a higher temperature. The test criteria are used to extrapolate an observed pressure rise at greater than or equal to $40^{\circ} \mathrm{C}$ to alternative estimates of the corrosion reaction rate that may be observed at $75^{\circ} \mathrm{C}$. The estimates assume alternative phenomena control the reaction rate that results in the observed pressure rise. The alternatives considered are as follows.

- The corroding uranium surface area limits reaction rate.

- The water vapor flow, from fuel crevices modeled as clad defects, to reacting uranium surfaces 1 imits reaction rate.

- The water vapor flow, from fuel crevices modeled as pores filled with granular material, to reacting uranium surfaces 1 imits reaction rate.

- The diffusion of water vapor to reacting uranium surfaces limits reaction rate.

The test must indicate that thermal excursions will be avoided while an MCO is maintained at $75^{\circ} \mathrm{C}$ with stagnant helium during transport acceptance testing.

Duncan and Ball (1997) indicates that thermal stability of fuel and scrap in an MCO can be maintained with significant margin for the reacting fuel surface area if the tempered water system is at $50^{\circ} \mathrm{C}$ and the MCO is backfilled with helium. Figure 9.5-1 duplicates Figure 5-2 of Attachment $A$ to Duncan and Ball (1997), indicating the variation of the theoretical ignition temperature (point of thermal instability) for a scrap basket as a function of the effective reacting surface area (product of the fuel surface area and reaction rate law multiplier).

The gas evolved into the vapor space may be either hydrogen or water vapor. The uranium corrosion reaction consumes approximately one mole of water to produce approximately one mole of hydrogen. This stoichiometry allows an evaluation to conservatively assume observed gas generation rates are either a11 hydrogen, or a 11 water vapor, without modification of the molar gas rates. 
HNF-1851, Rev 0

Figure 9.5-1. Incipient ignition temperature for a scrap basket with copper fin (based on calculation in Duncan and Ba11, 1997)

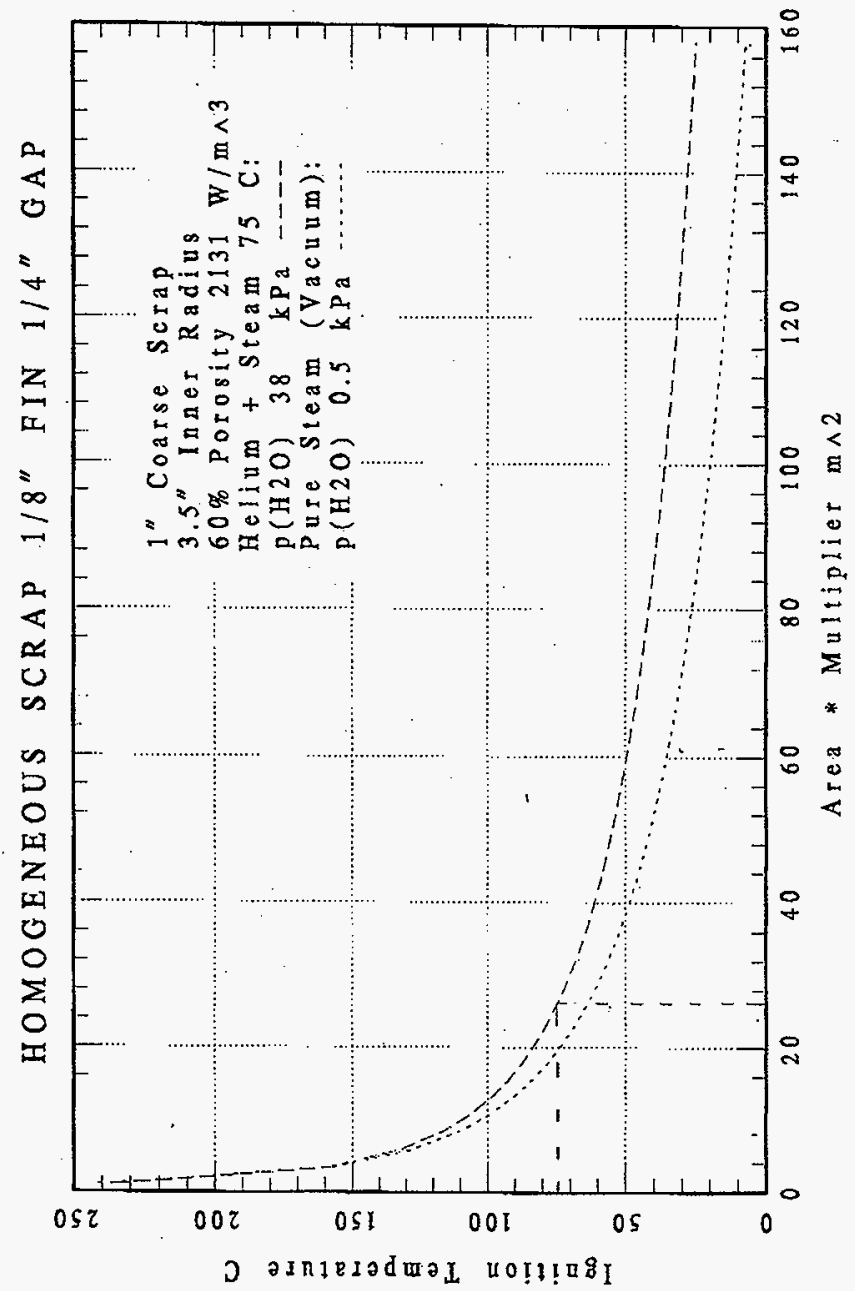

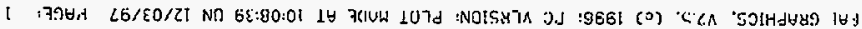




$$
\text { HNF-1851, Rev } 0
$$

Duncan (1997) describes the uranium reaction kinetics for oxygen free water vapor as follows.

$$
\text { Rate }=A \xi K
$$

where: $\quad A=$ surface area, $\mathrm{cm}^{2}$

$\xi=$ reactivity enhancement factor, dimensionless

$\mathrm{K}=$ rate constant, $\mathrm{mg}(\mathrm{wt}$ gain $) / \mathrm{hr}-\mathrm{cm}^{2}$

The rate constant for oxygen free water vapor is defined by

$$
\log _{10} K=4.33-2144 / T+0.5 \log _{10} P
$$

where: $T=$ temperature, $K$

$\mathrm{P}=$ partial pressure water vapor, $\mathrm{kPa}$

A conservative estimate of the thermal stability in a scrap basket is found from Figure 9.5-1. This occurs when $A \xi=26 \mathrm{~m}^{2}=260,000 \mathrm{~cm}^{2}$. At $75^{\circ} \mathrm{C}=$ $348 \mathrm{~K}$, the saturation pressure of steam is $5.6172 \mathrm{psia}$, or $38.7 \mathrm{kPa}$. Based on the rate equations above, a scrap basket is predicted to be thermally stable when the generated reaction heat is less than or equal to that produced by a reaction rate of $23,900 \mathrm{mg}$ (wt gain)/hr. Details of this calculation are shown as follows.

$$
\begin{aligned}
& \log _{10} K=4.33-\frac{2144}{348}+0.5 \log _{10}(38.7) \\
& =-1.037 \\
& K=0.0918 \mathrm{mgwtgain} / \mathrm{hr}-\mathrm{cm}^{2} \\
& \text { Rate }\left.\right|_{75^{\circ} \mathrm{C}}=\left(260,000 \mathrm{~cm}^{2}\right)(0.0918)=23,900 \mathrm{mgwtgain} / \mathrm{hr}
\end{aligned}
$$

Based on reaction stoichiometry, $32 \mathrm{~g}$ weight gain will be observed per gmol uranium reacted. Therefore, the reaction rate is equivalent to $0.75 \mathrm{gmol}$ $\mathrm{U}$ reacted $/ \mathrm{hr}$. Details of this calculation are shown as follows.

$$
\begin{aligned}
\text { U Rate }\left.\right|_{75^{\circ} \mathrm{C}} & =\frac{23,900 \mathrm{mgwtgain} / \mathrm{hr}}{(1000 \mathrm{mg} / \mathrm{g})(32 \mathrm{gwtgain} / \mathrm{gmolU})} \\
& =0.75 \mathrm{gmol} / \mathrm{hr}
\end{aligned}
$$

Assuming 2 gmol $\mathrm{H}_{2}$ produced per mole uranium reacted, the reaction rate that is thermally stable within a scrap basket at $75^{\circ} \mathrm{C}$ is characterized by a gas generation rate of $1.5 \mathrm{gmol} / \mathrm{hr}$. This gas or vapor generation rate is used as a basis for determining if lower temperature measurements predict an MCO will be thermally stable at $75^{\circ} \mathrm{C}$.

Note that the reaction rate derived above considers all reaction heat to be generated in the scrap basket. This assumption is conservative in that a portion of the reaction rate measured by a total pressure rise test would be expected to occur in 211 baskets. However, the pressure rise test can not discriminate as to which basket reactions are occurring. 


\subsubsection{Reacting Surface Area Limits Reaction}

As indicated above, an MCO that passes the pressure rise test at a lower temperature $\left(40^{\circ} \mathrm{C}\right.$ is used for this calculation) can not generate more than $1.5 \mathrm{gmol} / \mathrm{hr}$ gas when raised to $75^{\circ} \mathrm{C}$. This could be the result of liquid water reacting with uranium to form hydrogen that evolves into the MCO void region, or water vapor transferring to the void region that may subsequently react with uranium metal. Assuming the observed pressure increase results from liquid water reacting with uranium, the corroding surface area constrains the reaction rate. The effect of increasing the system temperature to $75^{\circ} \mathrm{C}$ can be estimated from the reaction kinetic equation, assuming the same reacting surface area will limit reaction rates, resulting in the following gas generation estimate (note that the partial pressure of water is $38.7 \mathrm{kPa}$ and $7.42 \mathrm{kPa}$ at $75^{\circ} \mathrm{C}$ and $40^{\circ} \mathrm{C}$, respectively).

$$
\begin{aligned}
\text { Gas rate }\left.\right|_{40} & \left.=\frac{A \xi 10^{4.33} 10^{-\frac{2144}{313}} \sqrt{P_{\text {sat }, 40}}}{A \xi 10^{4.33} 10^{-\frac{2144}{348}} \sqrt{P_{\text {sat, } 75}}} \text { (Gas rate }\left.\right|_{75}\right) \\
& =10^{\left(\frac{2144}{348}-\frac{2144}{313}\right)} \sqrt{\frac{7.42}{38.7}}(1.5 \mathrm{gmol} / / \mathrm{hr}) \\
& =0.134 \mathrm{gmal} / \mathrm{hr}
\end{aligned}
$$

The gas evolution rate calculated by Equation $9.5-1$ is transiated into an observed pressure rise rate using Figure 9.4-2. Therefore, assuming the MCO void volume is conservatively at $1,000 \mathrm{~L}$ a measured pressure rise rate of 1 ess than 2.6 torr $/ \mathrm{hr}$ would indicate that stability can be maintained at $75^{\circ} \mathrm{C}$. The pressure rise criterion could be increased by using a less conservative MCO void volume as a basis. As the void volume approaches a minimum of $500 \mathrm{~L}$, the pressure rise criterion derived from Equation 9.5-1 increases to 5.2 torr $/ \mathrm{hr}$.

\subsubsection{Orifice Flow Model Limits Reaction}

Since the pore model based on flow through a porous bed is based on flow resulting from pressure differences, no flow of water vapor to reacting surfaces would be predicted by this model when the MCO pressure is less than the saturation pressure of steam, independent of a pressure rise test results. As indicated in Section 9.1.4, the orifice flow model can be assumed to 1 imit the flow of water vapor from fuel crevices to reacting surfaces and extrapolate the rate to transport acceptance test conditions at pressures less than half the saturation pressure of steam. An extrapolation can be developed based on assuming the observed gas flow rate results from a number of constant diameter cladding defects. The mass flow rate from $\mathrm{N}$ cladding defects is provided by Equation 9.1-4, assuming choked flow through an orifice. 


$$
\begin{gathered}
\text { HNF-1851, Rev } 0 \\
W=C A_{2} p_{1} \sqrt{\left(\frac{g_{c} k M}{R T}\right)\left(\frac{2}{k+1}\right)^{\frac{(k+1)}{(k-1)}}}
\end{gathered}
$$

Saturated steam properties of $p_{1}=38.7 \mathrm{kPa}$ at $75^{\circ} \mathrm{C}$ and $p_{1}=7.42 \mathrm{kPa}$ at $40^{\circ} \mathrm{C}$ are used to define the properties upstream of the orifice. The mass flow rate change by increasing the temperature to $75^{\circ} \mathrm{C}$ is estimated as follows, noting that the number and size of constant diameter orifices modeling defects drop out of the ratio.

$$
\left.w\right|_{40}=\left.\frac{\left.\left(\frac{p_{1}}{\sqrt{T}}\right)\right|_{40}}{\left.\left(\frac{p_{1}}{\sqrt{T}}\right)\right|_{75}} w\right|_{75}=\frac{\frac{7.42}{\sqrt{313}}}{\frac{38.7}{\sqrt{348}}}(1.5)=0.30 \mathrm{gmol} / \mathrm{hr}
$$

The gas evolution rate calculated by Equation $9.5-2$ is translated into an observed pressure rise rate using Figure 9.4-2. Therefore, assuming the MCO void volume is conservatively at $1,000 \mathrm{~L}$ a measured pressure rise rate of less than 5.9 torr/hr would indicate that stability can be maintained at $75^{\circ} \mathrm{C}$. As the void volume approaches a minimum of $500 \mathrm{~L}$, the pressure rise criterion derived from Equation $9.5-2$ increases to 11.8 torr $/ \mathrm{hr}$.

This model assumes critical flow through orifices which would occur when the MCO pressure is less than 160 torr at $75^{\circ} \mathrm{C}$. This model would predict lower water vapor flow rates from orifices for pressures above 160 torr. Therefore, the orifice flow model would also predict that stable fuel temperatures can be maintained in an $\mathrm{MCO}$ at $75^{\circ} \mathrm{C}$ when the pressure is greater than 160 torr.

\subsubsection{Porous Bed Flow Model}

Since the pore model based on flow through a porous bed is based on flow resulting from pressure differences, no flow of water vapor to reacting surfaces would be predicted by this model when the MCO pressure is less than the saturation pressure of steam, independent of a pressure rise test results.

\subsubsection{Pore Diffusion Model}

Diffusion from multiple fuel crevices can be assumed to limit the flow of water vapor to reacting surfaces and extrapolate the rate to transport acceptance test conditions. Vacuum test condition at $40^{\circ} \mathrm{C}$ do not provide a true indication of the diffusion rate. However, a conservative bound of the impact of diffusion on higher temperature reaction rates can be derived by assuming the measured bulk flow rate at $40^{\circ} \mathrm{C}$ bounds the diffusion rate when an 


$$
\text { HNF-1851, Rev } 0
$$

MCO is backfilled with helium. The extrapolation is based on assuming the observed gas flow rate results from a number of constant diameter pores in the fue $\}$. The mass flow rate from $N$ pores is provided by adapting Equation 9.3-2.

Flow from $N$ pares $=N(A) N_{A}$

$$
=N(A)\left[-\frac{D_{G} P}{R T B_{F}} \ln \left(1-\frac{P_{i}}{P}\right)\right.
$$

Noting that for comparison at different conditions, $N, A, R$, and $B_{F}$ are constants and noting from Equation 9.3-7 that $D_{G} P=\left(1.825 \times 10^{-4}\right) \mathrm{T}^{2 / 3}$, the predicted diffusion rate increase can be estimated from the following equation.

$$
\begin{aligned}
\text { Massrate }_{40} & =\frac{\left[\sqrt{T} \ln \left(1-\frac{P_{i}}{P}\right)\right]_{40}}{\left[\sqrt{T} \ln \left(1-\frac{P_{i j}}{P}\right)\right]_{75}} \text { Massrate }\left.\right|_{75} \\
& =\frac{\left[\sqrt{313} \ln \left(1-\frac{7.42}{101.325}\right)\right]}{\left[\sqrt{348} \ln \left(1-\frac{38.7}{101.325}\right)\right]}(1.5)=0.22 \mathrm{gmol} / \mathrm{hr}
\end{aligned}
$$

The water vapor evolution rate calculated by Equation 9.5-3 can be translated into an observed pressure rise rate using Figure 9.4-2. Therefore, assuming the $M C O$ void volume is conservatively at $1,000 \mathrm{~L}$ a measured pressure rise rate of less than 4.3 torr $/ \mathrm{hr}$ would indicate that stability can be maintained at $75^{\circ} \mathrm{C}$. The pressure rise criterion could be increased by using a less conservative MCO void volume as a basis. As the void volume approaches a minimum of $500 \mathrm{~L}$, the pressure rise criterion derived from Equation 9.5-3 increases to 8.6 torr $/ \mathrm{hr}$. 


\section{DISTRIBUTION SHEET}

\begin{tabular}{|c|c|c|c|c|c|}
\hline \multirow{2}{*}{$\begin{array}{l}\text { To } \\
\text { Distribution }\end{array}$} & \multirow{2}{*}{\multicolumn{2}{|c|}{$\begin{array}{l}\text { From } \\
\text { Process Engineering }\end{array}$}} & & \multicolumn{2}{|c|}{ Page 1 of 1} \\
\hline & & & & \multicolumn{2}{|c|}{ Date $11 / 25 / 97$} \\
\hline \multirow{2}{*}{\multicolumn{4}{|c|}{$\begin{array}{l}\text { Project Title/Work Order } \\
\text { Cold Vacuum Drying Re }\end{array}$}} & \multicolumn{2}{|c|}{ EDT No. 616193} \\
\hline & & & & \multicolumn{2}{|c|}{ ECN No. N/A } \\
\hline \multicolumn{2}{|c|}{ Name } & $\begin{array}{c}\text { Text } \\
\text { With All } \\
\text { Attach. }\end{array}$ & Text Only & $\begin{array}{l}\text { Attach./ } \\
\text { Appendix } \\
\text { Only }\end{array}$ & $\begin{array}{l}\text { EDT/ECN } \\
\text { Only }\end{array}$ \\
\hline
\end{tabular}

DE\&S Hanford, Inc.

D. E. Ball

D. W. Bergmann

D. R. Duncan

J. R. Frederickson

R. P Omberg

W. H. Rasin

D. W. Smith

J. A. Swenson

Fluor Daniel Northwest

R. D. Crowe

Numatec Hanford Corp.
G. P. Chevrier
J. J. Irwin
C. R. Miska
C. Pili-Vincens

SGN Eurisys Services Corporation

E. A. Nelson

A. L. Pajunen
$\mathrm{R} 3-86$

$\times 3-79$

R3-86

R3-86

R3-11

R3-15

R3-15

R3-15

$x$
$X$
$X$
$x$
$X$

$x$

R3-11 $X$

R3-86

$\mathrm{R} 3-86$

R3-86

$\mathrm{R} 3-86$

$x$
$X$
$X$
$x$

R3-86

R3-86

$x$
$X$ 